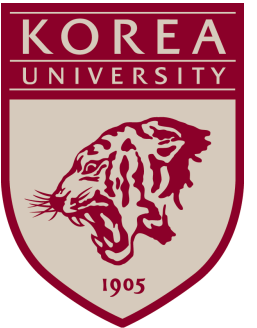

Discussion Paper Series

No. 1101

April 2011

Competitive mixed bundling of vertically differentiated products

\author{
Illtae Ahn and Kiho Yoon
}

The Institute of Economic Research - Korea University

Anam-dong, Sungbuk-ku, Seoul, 136-701, South Korea, Tel: (82-2) 3290-1632, Fax: (82-2) 928-4948

Copyright (c) 2011 IER. 


\title{
Competitive mixed bundling of vertically differentiated products
}

\author{
Illtae Ahn \\ Department of Economics, Chung-Ang University \\ Heuksuk-dong, Dongjak-gu, Seoul, Korea 156-756 \\ illtae@cau.ac.kr \\ and \\ Kiho Yoon \\ Department of Economics, Korea University \\ Anam-dong, Sungbuk-gu, Seoul, Korea 136-701 \\ kiho@korea.ac.kr \\ http://econ.korea.ac.kr/ kiho
}

This version: April 2011

First version: January 2011

\begin{abstract}
We examine mixed bundling in a competitive environment that incorporates vertical product differentiation. We show that, compared to the equilibrium without bundling, (i) prices, profits and social welfare are lower, whereas (ii) consumer surplus is higher in the equilibrium with mixed bundling. In addition, the population of consumers who purchase both products from the same firm is larger in the equilibrium with mixed bundling. Further, when the quality gap between brands narrows under no bundling and symmetric mixed bundling, prices and profits decrease but social welfare and consumer surplus increase. When quality differentiation is asymmetric across products, however, complicated effects occur on prices and profits due to strategic interdependence that mixed bundling creates.
\end{abstract}

JEL Classification: D43, L13

Keywords: mixed bundling, vertical differentiation, quality advantage, competitive bundling 


\section{Competitive mixed bundling of vertically differentiated products}

\section{Introduction}

Mixed bundling is commonly observed in the real world. Classic examples include stereo systems, software suites, fast-food restaurant meals, and concert tickets, which are typically available at a discount as packages alongside with individual products. Moreover, the strategic use of mixed bundling in oligopolistic environments is gaining increasing importance in the era of digital convergence. For example, many firms in the telecommunications and broadcasting industries offer the "triple play" service of combining telephony, Internet access, and broadcasting with bundle discounts to attract new customers and to widen their business sphere.

There is an extensive literature on bundling. ${ }^{1}$ Adams and Yellen (1976), Schmalensee (1982), McAfee, McMillan, and Whinston (1989), and Bakos and Brynjolfsson (1999) establish that the monopolist may use mixed bundling as a price discrimination device to increase profits. Other papers including Whinston (1990) and Nalebuff (2004) study how the monopolist makes strategic use of pure bundling or tying to foreclose competitors. These papers analyze the industry structure in which one firm holds a monopoly power or sufficient market power.

The strand of literature that is closest to the current paper is those that study mixed bundling in a more competitive and symmetric environment. These works include Matutes and Regibeau (1992), Anderson and Leruth (1993), Economides (1993), Reisinger (2006), Gans and King (2006), and Thanassoulis (2007). ${ }^{2}$ In these papers, each of two symmetric and horizontally differentiated firms produces its own brand of two products. ${ }^{3}$ Matutes and Regibeau (1992) study mixed bundling in the "mix and match" model of Matutes and Regibeau (1988) and show that, for a wide range of parameters, firms choose to offer bundle discounts even though their profits would be higher if they could agree not to be engaged in mixed bundling. They also show that firms' propensity to bundle is excessive from a social welfare perspective. Anderson and Leruth (1993) and Economides (1993) consider mixed bundling in somewhat different models but arrive at basically the same conclusion. ${ }^{4}$ Reisinger (2006) is yet another paper that studies mixed bundling in a circular-city model with a discussion of location choice. Thanassoulis (2007) extends Matutes and Regibeau's location model by introducing small buyers who only desire one of the component products and by distinguishing between firm-specific and product-specific preferences. This paper discovers that, compared to the equilibrium without bundling, profits are higher but consumer surplus is lower with mixed bundling under firm-specific preferences. The conclusions are reversed under product-specific preferences, with which the other papers are concerned.

In Gans and King (2006), two unrelated products are produced by four firms. Pairs of firms may agree to offer bundle discounts when their products are purchased together. In comparison to the papers above which assume that bundle discounts as well as stand-alone

\footnotetext{
1 Excellent recent surveys include Kobayashi (2005) and Stole (2007).

2 A recent paper by Armstrong and Vickers (2010) is also relevant.

3 As a matter of fact, Gans and King (2006) first consider four independent firms and then integrated firms. See the next paragraph.

4 Matutes and Reibeau (1992) adopts the Hotelling location model; Anderson and Leruth (1993), the “discrete choice" model; and Economides (1993), the linear demand model.
} 
prices are set simultaneously, firms in this paper first decide on the level of bundle discounts and then simultaneously announce their stand-alone prices. Gans and King show that both pairs of firms offer bundle discounts such that all consumers purchase both products either from one pair or from the other in equilibrium. However, if both pairs of firms are integrated, they choose not to offer bundle discounts in equilibrium, contrary to the findings above.

No paper, however, that the authors are aware has studied mixed bundling in a competitive environment that incorporates vertical product differentiation. This is surprising since vertical differentiation in quality is widely observed in competitive mixed bundling. In fact, it would be an exception rather than the rule that the products offered by different firms have the same quality. Vertical differentiation may result from the product design or consumers' perception due to installed base, incumbency, or firm's reputation. As an example, consider the broadcasting and telecommunications industry. Both the phone company and the cable company offer the telephony service and the broadcasting service. In many instances, the phone company offers a high-quality telephony service, whereas the cable company offers a high-quality broadcasting service. The telecommunications industry itself in many countries, say in Korea, is another example of a vertically differentiated oligopoly engaged in mixed bundling. Korea Telecom (KT) has market dominance in fixed-line telecommunications, whereas SK Telecom (SKT) holds the dominant position in mobile telecommunications. In recent years, each firm has expanded into the other's turf by merger and acquisitions, and started to offer bundles alongside with stand-alone telephony services. Consumers' general perception is such that KT's quality of fixed-line telephony service is superior, but SKT's mobile telephony service is superior.

To analyze the effects of competitive mixed bundling in vertically differentiated product markets, we consider a model in which two firms offer their own brands of two products. One firm offers a high-quality brand of product 1 , whereas the other offers a high-quality brand of product 2. The products are unrelated in that (i) production costs are not related and (ii) consumers' valuations for the two products are independent. Hence, we rule out the rationale for bundling arising out of production and/or consumption efficiency.

After introducing the model in Section 2, we consider the benchmark case in which the firms do not offer bundle discounts in Section 3. We then analyze the case of mixed bundling in Section 4: We start in Section 4.1 with the case when the firms' quality advantages are symmetric. In Section 4.2, we allow for asymmetric quality advantages. That is, the magnitude of the quality gap between the brands of product 1 may be different from that between the brands of product 2. It is shown that, compared to the equilibrium without bundling, (i) prices, profits and social welfare are lower, whereas (ii) consumer surplus is higher in the equilibrium with mixed bundling. In addition, the population of consumers who purchase both products from the same firm is larger in the equilibrium with mixed bundling. These results are in line with those obtained in the previous literature, but the reason is quite different since we consider vertical differentiation. ${ }^{5}$

We conduct a comparative static analysis with respect to changes in quality differentiation parameters. Let $A$ be the quality gap between the brands of one product and $B$ be the quality gap between the brands of another product. We show in Section 3 that, when firms do not offer bundle discounts, equilibrium prices and profits decrease but social welfare and consumer surplus increase as $A$ or $B$ gets smaller. The reason is basically that firms compete more intensely when brands become more substitutable. We show in Section 4.1 for symmetric mixed bundling that, with respect to a decrease in $A=B$, the direction of changes

\footnotetext{
${ }^{5}$ Please refer to Section 4.1 for more details.
} 
in these equilibrium variables is the same as that in the previous section but the rate of changes is different. In particular, prices and profits decrease more slowly whereas social welfare increases more rapidly as $A=B$ decreases. This is due to strategic interdependence between the products that mixed bundling creates. ${ }^{6}$

The asymmetric quality differentiation in Section 4.2 yields more interesting observations with regard to the comparative statics. Let us assume without loss of generality that $A \geq B$. We first show that a decrease in $A$ reduces both firms' profits, whereas a decrease in $B$ increases one firm's profits but reduces the other's profits. The reason is that a decrease in $A$ narrows the quality gap between bundles and thus intensifies competition. In contrast, a decrease in $B$ widens the quality gap which leads to lessened competition, favoring the firm in a competitively advantageous position. We also show that the effect of a decrease in $A$ on prices is different from that of a decrease in $B$, due to rather complicated strategic interdependence between the products. ${ }^{7}$ We additionally establish that the equilibrium prices with mixed bundling converge to those without bundling when the quality gap in one product vanishes, that is, when $B$ gets close to zero.

\section{The model}

Two firms, $N$ and $S$, each offer their own brand of two products, 1 and 2. The products are differentiated in terms of their quality. That is, firm $N$ offers a high-quality brand of product 1 whereas firm $S$ offers a high-quality brand of product 2 . We assume that the marginal cost of production is zero for both firms. Let $p_{i}^{k}$ denote the (stand-alone) price charged by firm $k=N, S$ for product $i=1,2$ and $\delta^{k}$ denote the bundle discount offered by firm $k=N, S$ when the two products are sold as a package. We assume that $p_{i}^{k} \geq 0$ and $\delta^{k} \geq 0$. The firms set their prices and bundle discounts simultaneously.

There is a population of consumers who purchase at most one unit of each of the two products. We normalize the total population of consumers to be 1 . Consumers differ in their "taste for quality." A consumer's preference is denoted by $(x, y) \in[0,1] \times[0,1]$, where $x$ represents the valuation for product 1 and $y$ represents that for product 2 . We assume that consumers' valuations for the products are uniformly distributed on a unit square $[0,1] \times[0,1]$. Hence, we assume that the products are independent in the sense that consumers' preferences for the two products are independent. A consumer with the preference $(x, y)$ enjoys a gross payoff of $v_{1}+a^{k} x$ when she purchases one unit of product 1 from firm $k=N, S$, and she enjoys a gross payoff of $v_{2}+b^{k} y$ when she purchases one unit of product 2 from firm $k=N, S$. We assume that $v_{1}$ and $v_{2}$ are sufficiently large such that every consumer purchases one unit of each of the two products. Hence, a consumer may purchase (i) one unit of product 1 from $N$ and one unit of product 2 from $S$; (ii) one unit of each of the two products from $N$; (iii) one unit of each of the two products from $S$; or (iv) one unit of product 1 from $S$ and one unit of product 2 from $N$. Accordingly, a consumer with the preference $(x, y)$ enjoys a net payoff as follows:

(i) $v_{1}+v_{2}+a^{N} x+b^{S} y-\left(p_{1}^{N}+p_{2}^{S}\right)$,

\footnotetext{
${ }^{6}$ Please refer to Sections 4.1 and 4.2 for more details.

7 Please refer to Section 4.2 for more details.
} 
(ii) $v_{1}+v_{2}+a^{N} x+b^{N} y-\left(p_{1}^{N}+p_{2}^{N}-\delta^{N}\right)$,

(iii) $v_{1}+v_{2}+a^{S} x+b^{S} y-\left(p_{1}^{S}+p_{2}^{S}-\delta^{S}\right)$, or

(iv) $v_{1}+v_{2}+a^{S} x+b^{N} y-\left(p_{1}^{S}+p_{2}^{N}\right)$

where $a^{N}$ and $b^{N}$ are firm $N$ 's quality parameters for products 1 and 2, respectively, and $a^{S}$ and $b^{S}$ are firm $S$ 's quality parameters for products 1 and 2, respectively. Here, $a^{N}>a^{S}$, but $b^{N}<b^{S}$, that is, firm $N$ has a quality advantage in product 1 , whereas firm $S$ has a quality advantage in product 2. We normalize $a^{N}=b^{S}=1$ for convenience. Thus,

Assumption. $a^{N}=b^{S}=1$ and $0<a^{S}, b^{N}<1$.

We make several notational conventions. Firstly, we denote the parameters $a^{S}$ and $b^{N}$ as $a$ and $b$, respectively. Secondly, we denote the bundle price $p_{1}^{k}+p_{2}^{k}-\delta^{k}$ as $r^{k}$ for $k=N, S$. Then, a consumer's net payoff for the four purchase scenarios discussed above, as suppressing the common component $v_{1}+v_{2}$, can be rewritten as follows:

(i) $x+y-p_{1}^{N}-p_{2}^{S}$,

(ii) $x+b y-r^{N}$,

(iii) $a x+y-r^{s}$, and

(iv) $a x+b y-p_{1}^{S}-p_{2}^{N}$.

Let us denote the population of consumers who purchase product 1 from firm $N$ and product 2 from firm $S$ by $D^{N S}$, the population of consumers who purchase both products from firm $N$ by $D^{N N}$, and so on.

\section{Equilibrium without bundling}

As a benchmark, we first consider the case when no firm offers a bundle discount, that is, $\delta^{N}=\delta^{S}=0$. Figure 1 shows the consumer's choices without bundling. Consumers with $x \geq\left(p_{1}^{N}-p_{1}^{S}\right) /(1-a)$ purchase product 1 from firm $N$, whereas consumers with $x<\left(p_{1}^{N}-p_{1}^{S}\right) /(1-a)$ purchase product 1 from firm $S$. Similarly, consumers with $y \geq\left(p_{2}^{S}-p_{2}^{N}\right) /(1-b)$ purchase product 2 from firm $S$, whereas consumers with $y<\left(p_{2}^{S}-p_{2}^{N}\right) /(1-b)$ purchase product 2 from firm $N$. 


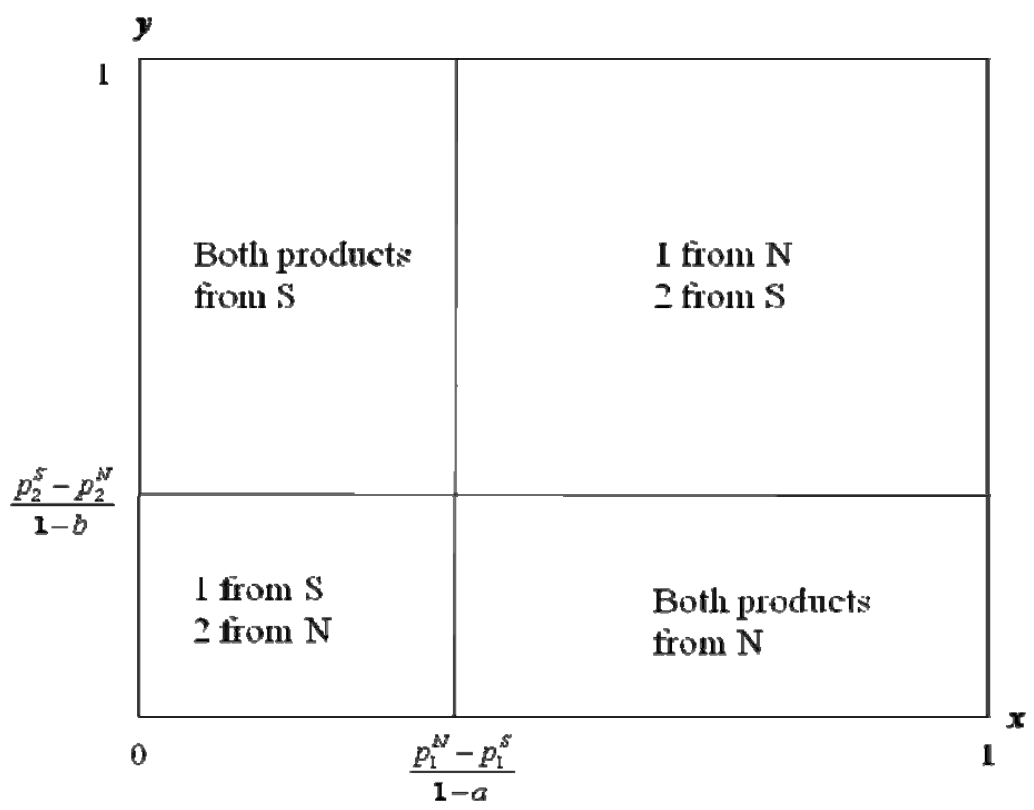

Figure 1: The pattern of consumer choice without bundling

Hence, the firms’ profits are

$$
\pi^{N}=p_{1}^{N}\left(1-\frac{p_{1}^{N}-p_{1}^{S}}{1-a}\right)+p_{2}^{N} \frac{p_{2}^{S}-p_{2}^{N}}{1-b} ; \pi^{S}=p_{1}^{S} \frac{p_{1}^{N}-p_{1}^{S}}{1-a}+p_{2}^{S}\left(1-\frac{p_{2}^{S}-p_{2}^{N}}{1-b}\right) .
$$

We have:

Proposition 1. The equilibrium is given by

$$
\begin{aligned}
& p_{1}^{N}=\frac{2(1-a)}{3}, p_{1}^{S}=\frac{1-a}{3}, p_{2}^{N}=\frac{1-b}{3}, p_{2}^{S}=\frac{2(1-b)}{3} \\
& D^{N S}=\frac{4}{9}, D^{N N}=D^{S S}=\frac{2}{9}, D^{S N}=\frac{1}{9} ; \pi^{N}=\frac{5-4 a-b}{9}, \pi^{S}=\frac{5-a-4 b}{9} .
\end{aligned}
$$

Proof. The equilibrium can be easily obtained by setting $\partial \pi^{k} / \partial p_{i}^{k}=0$ for $i=1,2$ and for $k=N, S$. Q.E.D.

Observe that the equilibrium prices $p_{i}^{N}$ and $p_{i}^{S}$ of product $i$ depend only on the quality differentiation parameter for product $i$, not on that for the other product. In this sense, competition between the firms is completely separated across the products, that is, there is no strategic interdependence between the products. This aspect of competition changes when the firms offer bundle discounts. Observe also that when the quality differentiation between the firms diminishes (i.e., as $a$ or $b$ increases toward 1), both prices and profits decrease. The reason is that the firms compete more vigorously as the products become more substitutable.

Social welfare without bundling is given by 


$$
\int_{0}^{1 / 3} a x d x+\int_{1 / 3}^{1} x d x+\int_{0}^{1 / 3} b y d y+\int_{1 / 3}^{1} y d y=\frac{16+a+b}{18}
$$

Consumer surplus, which is equal to social welfare net of the firms' profits, is $(11 a+11 b-4) / 18 .{ }^{8}$ Both social welfare and consumer surplus increase as $a$ or $b$ increases.

\section{Equilibrium with mixed bundling}

We now assume that the firms are engaged in mixed bundling. Then the consumer's choice can be summarized by the following two diagrams. Figure 2 depicts the case when $\min \left\{r^{N}, r^{S}\right\}>p_{1}^{S}+p_{2}^{N}$, whereas Figure 3 depicts the case when $\min \left\{r^{N}, r^{S}\right\} \leq p_{1}^{S}+p_{2}^{N}$.

Figure 2 shows that consumers with high valuations for both products purchase product 1 from firm $N$ and product 2 from firm $S$. Consumers with a high valuation for product 1 but a low valuation for product 2 purchase both product from $N$, whereas those with a high valuation for product 2 but a low valuation for product 1 purchase both product from $S$. Finally, consumers with low valuations for both products purchase product 1 from $S$ and product 2 from $N$.

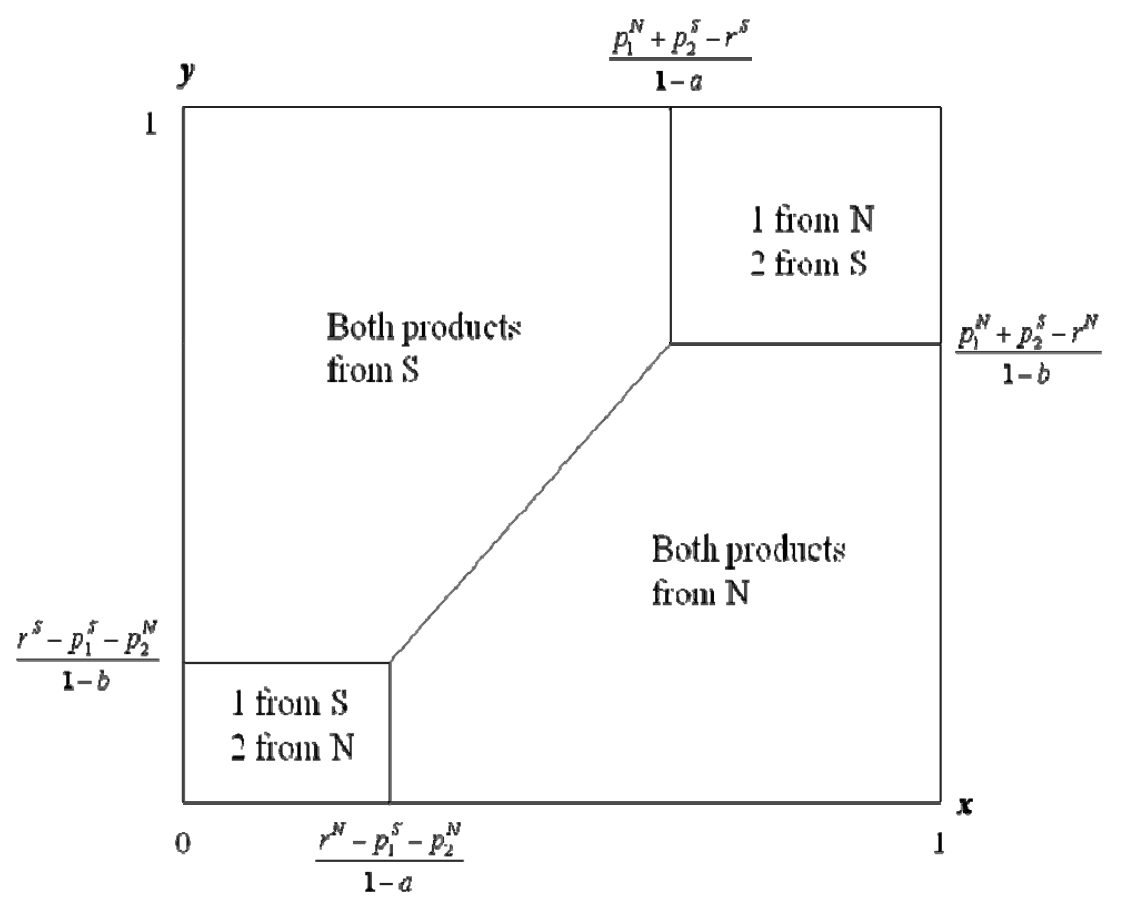

Figure 2: The pattern of consumer choice when $\min \left\{r^{N}, r^{S}\right\}>p_{1}^{S}+p_{2}^{N}$

Figure 3 shows similar purchase patterns, except that there do not exist consumers who

\footnotetext{
${ }^{8}$ Note that we suppress the common component $v_{1}+v_{2}$.
} 
purchase product 1 from $S$ and product 2 from $N$. Figure 3(a) shows the case when $r^{S} \leq r^{N}$, and Figure 3(b) shows the case when $r^{S}>r^{N}$. If a consumer purchased product 1 from $S$ and product 2 from $N$, then she would consume low-quality brands of both products. When $\min \left\{r^{N}, r^{S}\right\}=r^{S} \leq p_{1}^{S}+p_{2}^{N}$, she can consume a high-quality brand of product 2 (and a lowquality brand of product 1 ) with a lower total price by purchasing both products from $S$. Similarly, when $\min \left\{r^{N}, r^{S}\right\}=r^{N} \leq p_{1}^{S}+p_{2}^{N}$, she can consume a high-quality brand of product 1 (and a low-quality brand of product 2 ) with a lower total price by purchasing both products from $N$.

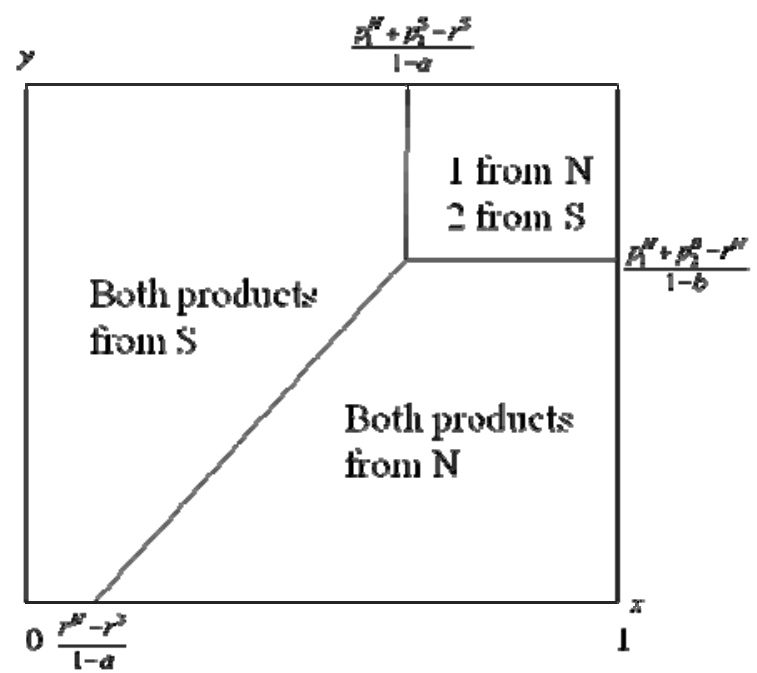

(a)

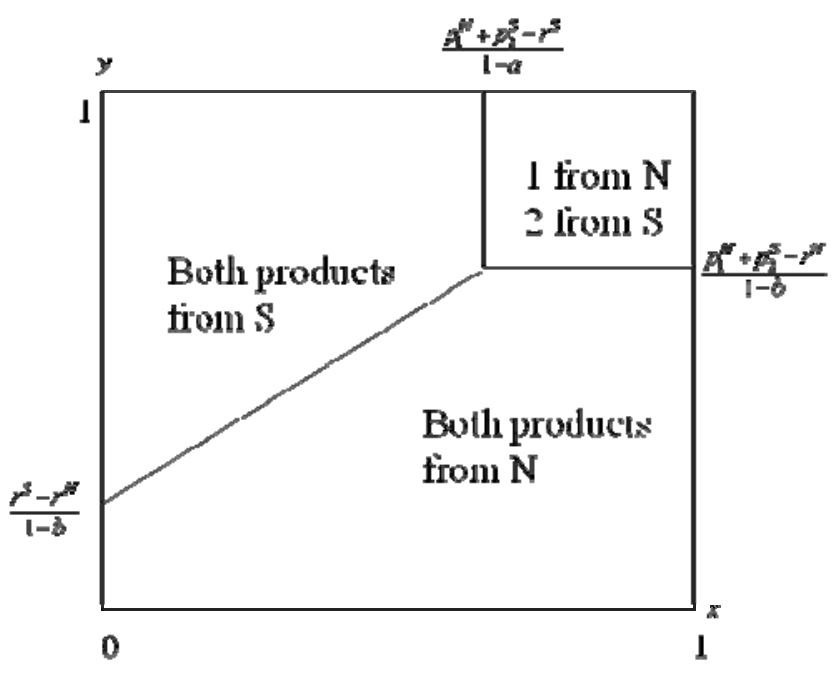

(b)

Figure 3: The pattern of consumer choice when $\min \left\{r^{N}, r^{S}\right\} \leq p_{1}^{S}+p_{2}^{N}$

The firms' profits when $\min \left\{r^{N}, r^{S}\right\}=r^{S} \leq p_{1}^{S}+p_{2}^{N}$ are

$$
\begin{aligned}
\pi^{N} & =p_{1}^{N} D^{N S}+r^{N} D^{N N}=p_{1}^{N}\left(1-\frac{p_{1}^{N}+p_{2}^{S}-r^{S}}{1-a}\right)\left(1-\frac{p_{1}^{N}+p_{2}^{S}-r^{N}}{1-b}\right) \\
& +r^{N}\left\{\frac{p_{1}^{N}+p_{2}^{S}-r^{N}}{1-b}\left(1-\frac{p_{1}^{N}+p_{2}^{S}-r^{S}}{1-a}\right)+\frac{1}{2} \frac{p_{1}^{N}+p_{2}^{S}-r^{N}}{1-b}\left(\frac{p_{1}^{N}+p_{2}^{S}-r^{S}}{1-a}-\frac{r^{N}-r^{S}}{1-a}\right)\right\}, \\
\pi^{S} & =p_{2}^{S} D^{N S}+r^{S} D^{S S}=p_{2}^{S}\left(1-\frac{p_{1}^{N}+p_{2}^{S}-r^{S}}{1-a}\right)\left(1-\frac{p_{1}^{N}+p_{2}^{S}-r^{N}}{1-b}\right) \\
& +r^{S}\left\{\frac{p_{1}^{N}+p_{2}^{S}-r^{S}}{1-a}\left(1-\frac{p_{1}^{N}+p_{2}^{S}-r^{N}}{1-b}\right)+\frac{1}{2} \frac{p_{1}^{N}+p_{2}^{S}-r^{N}}{1-b}\left(\frac{p_{1}^{N}+p_{2}^{S}-r^{S}}{1-a}+\frac{r^{N}-r^{S}}{1-a}\right)\right\},
\end{aligned}
$$

and their profits when $\min \left\{r^{N}, r^{S}\right\}=r^{N} \leq p_{1}^{S}+p_{2}^{N}$ can be analogously given. We can in fact establish that there cannot exist consumers who purchase low-quality brands of both products. That is, the situation in Figure 2 cannot happen in equilibrium.

Proposition 2. We have $\min \left\{r^{N}, r^{S}\right\} \leq p_{1}^{S}+p_{2}^{N}$ in equilibrium. 
Proof. See Appendix. Q.E.D.

The reason for this result is that, when $\min \left\{r^{N}, r^{S}\right\}>p_{1}^{S}+p_{2}^{N}$ holds, either firm $N$ can profitably increase $p_{2}^{N}$ to $\min \left\{r^{N}, r^{S}\right\}-p_{1}^{S}$ or firm $S$ can profitably increase $p_{1}^{S}$ to $\min \left\{r^{N}, r^{S}\right\}-p_{2}^{N}$ such that there exist no consumers who purchase low-quality brands of both products. By raising the prices of low-quality brands to make the option of buying lowquality brands of both products unattractive, the firms induce consumers to purchase bundles.

Observe that we have drawn Figure 3 under the presumption that $\left(p_{1}^{N}+p_{2}^{S}-r^{S}\right) /(1-a)<1$ and $\left(p_{1}^{N}+p_{2}^{S}-r^{N}\right) /(1-b)<1$. If one (or both) of these inequalities does not hold, then there exist no consumers who purchase product 1 from firm $N$ and product 2 from firm $S$. That is, all consumers purchase either $N$ 's bundle or $S$ 's bundle. We can establish, however, that this pure bundling outcome cannot happen in equilibrium.

Proposition 3. We have $\max \left\{\frac{p_{1}^{N}+p_{2}^{S}-r^{S}}{1-a}, \frac{p_{1}^{N}+p_{2}^{S}-r^{N}}{1-b}\right\}<1$ in equilibrium.

Proof. See Appendix. Q.E.D.

We next establish that $r^{S} \leq r^{N}$ when $a \leq b$. That is, if firm $N$ 's disadvantage in product 2 is smaller than firm $S$ 's disadvantage in product 1 , so that the quality of firm $N$ 's bundle is superior to that of firm $S$ 's bundle, then firm $N$ 's bundle price is higher in equilibrium. ${ }^{9}$

Proposition 4. Assume that $a \leq b$. We have $r^{S} \leq r^{N}$ in equilibrium.

Proof. See Appendix. $\quad$ Q.E.D.

\subsection{Mixed bundling under symmetric quality differentiation}

We now focus on the case in which the firms' quality disadvantages are symmetric, that is, $a=b$. Section 4.2 below addresses a more general case in which $a \neq b$. The following proposition characterizes the equilibrium outcome.

Proposition 5. Assume that $a=b$. The equilibrium is given by

$$
\begin{aligned}
& p_{1}^{N}=p_{2}^{S}=\frac{7(1-a)}{12}, r^{N}=r^{S}=\frac{2(1-a)}{3} ; \\
& D^{N S}=\frac{1}{4}, D^{N N}=D^{S S}=\frac{3}{8}, D^{S N}=0 ; \pi^{N}=\pi^{S}=\frac{19(1-a)}{48} .
\end{aligned}
$$

Proof. See Appendix. $\quad$ Q.E.D.

\footnotetext{
${ }^{9}$ Needless to say, we obtain the symmetric statement of $r^{s} \geq r^{N}$ when $a \geq b$.
} 
Let us compare the equilibrium outcome with mixed bundling to that without bundling. Since we are now focusing on the symmetric case for the moment, we need to set $a=b$ in Proposition 1. Observe first that the population of consumers who purchase both products from the same firm, i.e., $D^{N N}+D^{S S}$, increases from $4 / 9$ without bundling to $3 / 4$ with mixed bundling. This is because the firms compete to attract customers by offering bundle discounts. Hence, the bundle price $r^{N}=r^{S}=2(1-a) / 3$ is lower than the sum of stand-alone prices without bundling, which is equal to $1-a$. Note also that the stand-alone prices of highquality brands, $p_{1}^{N}=p_{2}^{S}$, is lower with mixed bundling. As a consequence, the firms' profits also decrease from $5(1-a) / 9$ without bundling to $19(1-a) / 48$ with mixed bundling. Most of the papers on competitive bundling, including Matutes and Regibeau (1992), Anderson and Leruth (1993), and Economides (1993), show that the firms' profits decrease in the equilibrium with mixed bundling compared to the equilibrium without bundling. We have established that this finding continues to hold when products are vertically differentiated.

Social welfare with mixed bundling is given by

$$
\begin{aligned}
& \int_{1 / 2}^{1} \int_{1 / 2}^{1}(x+y) d y d x+\int_{1 / 2}^{1} \int_{0}^{1 / 2}(x+b y) d y d x+\int_{0}^{1 / 2} \int_{0}^{x}(x+b y) d y d x \\
& +\int_{0}^{1 / 2} \int_{1 / 2}^{1}(a x+y) d y d x+\int_{0}^{1 / 2} \int_{x}^{1 / 2}(a x+y) d y d x=\frac{5+a}{6} .
\end{aligned}
$$

Recall from the previous section that social welfare without bundling is $(8+a) / 9$ when $a=b$. Since $(8+a) / 9-(5+a) / 6=(1-a) / 18>0$, social welfare decreases with mixed bundling. Mixed bundling has two countervailing effects on social welfare. On the one hand, it increases social welfare by eliminating the consumer group, represented by $D^{S N}$, who purchase low-quality brands of both products. On the other hand, it decreases social welfare by shrinking the consumer group, represented by $D^{N S}$, who purchase high-quality brands of both products. As can be seen from Figures 1 and 3 (with setting $a=b$ and $r^{N}=r^{S}$ ), the former effect increases social welfare by

$$
\begin{aligned}
& \int_{0}^{1 / 3} \int_{0}^{x}[x+b y-(a x+b y)] d y d x+\int_{0}^{1 / 3} \int_{0}^{y}[a x+y-(a x+b y)] d x d y \\
= & 2 \int_{0}^{1 / 3} \int_{0}^{x}(1-a) x d y d x=\frac{2(1-a)}{81}
\end{aligned}
$$

whereas the latter effect decreases social welfare by

$$
\begin{aligned}
& \int_{1 / 2}^{1} \int_{1 / 3}^{1 / 2}[x+y-(x+b y)] d y d x+\int_{1 / 3}^{1 / 2} \int_{1 / 3}^{x}[x+y-(x+b y)] d y d x \\
+ & \int_{1 / 2}^{1} \int_{1 / 3}^{1 / 2}[x+y-(a x+y)] d x d y+\int_{1 / 3}^{1 / 2} \int_{1 / 3}^{y}[x+y-(a x+y)] d x d y \\
= & 2\left[\int_{1 / 2}^{1} \int_{1 / 3}^{1 / 2}(1-b) y d y d x+\int_{1 / 3}^{1 / 2} \int_{1 / 3}^{x}(1-b) y d y d x\right] \\
= & \frac{13(1-a)}{162} .
\end{aligned}
$$

Thus, the latter effect dominates. It is clear that firms offer bundle discounts mainly to attract 
the consumers in $D^{N S}$ who have high valuations for both products. The extinction of consumer group $D^{S N}$ may be viewed as a by-product of firms' competition at this front. In other words, the latter effect is primary whereas the former effect is auxiliary. That's why social welfare decreases with mixed bundling.

In existing models of competitive mixed bundling with horizontal differentiation, such as Matutes and Regibeau (1992), Gans and King (2006), and Reisinger (2006), social welfare decreases with mixed bundling due to the distributive inefficiency. That is, social welfare decreases in these location models because some consumers purchase from firms in less desirable "locations," or in other words, consumers' "transport costs" become larger with bundle purchases. ${ }^{10}$ Thus, the reason for the decrease in social welfare is quite different.

Finally, consumer surplus with mixed bundling is $(1+23 a) / 24$. Thus, consumer surplus increases with mixed bundling by the amount of $19(1-a) / 72$. This is mainly due to price decreases under mixed bundling. As a matter of fact, it is straightforward to check that all consumers, including those who change their consumption patterns, are better off under mixed bundling.

Summarizing the discussion,

Proposition 6. Compared to the equilibrium without bundling, (i) prices, profits and social welfare are lower, whereas (ii) consumer surplus as well as the population of consumers who purchase both products from the same firm is larger in the equilibrium with mixed bundling.

As for comparative statics, observe in Proposition 5 that prices as well as profits decrease as $a=b$ increases. Observe also from the discussion above that both social welfare and consumer surplus increase as $a=b$ increases.

A noteworthy observation with respect to the effect of an increase in the parameter $a=b$ is that, although the direction of changes in all variables for the case with mixed bundling is the same as that for the case without bundling, the rate of changes is different across regimes. In particular, with an improvement of low-quality brands, i.e., with an increase in $a=b$, prices and profits decrease more slowly under mixed bundling than under no bundling. This is due to a strategic interdependence between the products that mixed bundling creates. Although a detailed discussion will be given later in Section 4.2 along with more comparative static results, the basic intuition is as follows. Recall from the discussion after Proposition 1 that competition between the firms is completely separated across the products without bundling. However, as we can see from Figure 3, product 1 offered by firm $N$ and product 2 offered by firm $S$ become complements with mixed bundling. This relationship mitigates price competition, compared to the case without bundling. Therefore, the negative effect of an increase in $a=b$ on $p_{1}^{N}$ or $p_{2}^{S}$ is relatively small under mixed bundling.

On the other hand, social welfare increases more rapidly under mixed bundling than under no bundling as $a=b$ increases. This is because more consumers benefit from a quality improvement under mixed bundling than under no bundling as the population of consumers who purchase both products from the same firm is larger under mixed bundling. To put it differently, although social welfare is lower under mixed bundling due to the shrinkage of the consumer group who purchase high-quality brands of both products, this effect is mitigated as the quality gap between the brands is narrowed. Finally, consumer surplus increases more

\footnotetext{
10 Matutes and Regibeau (1992) and Gans and King (2006) adopt the Hotelling location model. Reisinger (2006) adopts Salop's circular-city model.
} 
slowly under mixed bundling.

\subsection{Mixed bundling under asymmetric quality differentiation}

Let us return to the general case in which $a \neq b$. Assume without loss of generality that $a \leq b$. We relegate the characterization of equilibrium to the appendix since it is technical as well as quite complicated. The technical lemma in Appendix shows that the equilibrium prices with mixed bundling depend on the quality differentiation parameters $a$ and $b$ for both products. This result contrasts with that for the case without bundling, where the equilibrium prices of product $i$ depend only on the quality differentiation parameter for product $i$, not on that for the other product. A detailed discussion on this strategic interdependence will follow shortly.

Let us compare the equilibrium outcome with mixed bundling to that without bundling. In short, the result is the same as that for the symmetric case. We show in Proposition 7 that the equilibrium prices are lower and the population of consumers who purchase bundles is larger with mixed bundling.

Proposition 7. Assume that $a \leq b$. Compared to the equilibrium without bundling, (i) prices are lower, whereas (ii) the population of consumers who purchase both products from the same firm is larger in the equilibrium with mixed bundling.

Proof. See Appendix. Q.E.D.

We can obtain the same results for profits, social welfare, and consumer surplus as we have in Proposition 6. However, since the proof is tediously long albeit similar to that of Proposition 7, we only present some numerical results. ${ }^{11}$ In particular, we present the results for profits in Tables 1 and 2 below, but relegate the results on social welfare and consumer surplus to Tables 3 and 4 in the appendix for expositional brevity. Comparing these values with the corresponding equilibrium outcomes without bundling (given in Proposition 1), we can easily see that profits and social welfare are lower but consumer surplus is higher under mixed bundling.

<Table 1> $\pi^{N}$ under mixed bundling
\begin{tabular}{|c|cccccccccc|c|}
\hline$a \quad b$ & 0 & 0.1 & 0.2 & 0.3 & 0.4 & 0.5 & 0.6 & 0.7 & 0.8 & 0.9 \\
\hline 0 & 0.39583 & 0.39795 & 0.40059 & 0.40380 & 0.40763 & 0.41211 & 0.41726 & 0.42310 & 0.42959 & 0.43672 \\
0.1 & & 0.35625 & 0.35840 & 0.36113 & 0.36451 & 0.36859 & 0.37340 & 0.37897 & 0.38528 & 0.39231 \\
0.2 & & & 0.31667 & 0.31885 & 0.32170 & 0.32529 & 0.32969 & 0.33492 & 0.34101 & 0.34790 \\
0.3 & & & & 0.27708 & 0.27931 & 0.28232 & 0.28619 & 0.29101 & 0.29678 & 0.30351 \\
0.4 & & & & & 0.23750 & 0.23979 & 0.24301 & 0.24727 & 0.25265 & 0.25914 \\
0.5 & & & & & & 0.19792 & 0.20030 & 0.20382 & 0.20863 & 0.21479 \\
0.6 & & & & & & & 0.15833 & 0.16085 & 0.16485 & 0.17050 \\
0.7 & & & & & & & & 0.11875 & 0.12150 & 0.12630 \\
0.8 & & & & & & & & & 0.07917 & 0.08242 \\
0.9 & & & & & & & & & & 0.03958 \\
\hline
\end{tabular}

11 The proof is available upon request. 
$<$ Table $2>\pi^{S}$ under mixed bundling

\begin{tabular}{|c|cccccccccc|}
\hline$a$ & $b$ & 0.1 & 0.2 & 0.3 & 0.4 & 0.5 & 0.6 & 0.7 & 0.8 & 0.9 \\
\hline 0 & 0.39583 & 0.36759 & 0.33914 & 0.31055 & 0.28187 & 0.25318 & 0.22450 & 0.19594 & 0.16748 & 0.13921 \\
0.1 & & 0.35625 & 0.32800 & 0.29953 & 0.27090 & 0.24220 & 0.21352 & 0.18490 & 0.15642 & 0.12811 \\
0.2 & & & 0.31667 & 0.28840 & 0.25990 & 0.23123 & 0.20253 & 0.17387 & 0.14535 & 0.11701 \\
0.3 & & & & 0.27708 & 0.24880 & 0.22025 & 0.19157 & 0.16289 & 0.13428 & 0.10591 \\
0.4 & & & & & 0.23750 & 0.20919 & 0.18060 & 0.15190 & 0.12327 & 0.09482 \\
0.5 & & & & & & 0.19792 & 0.16957 & 0.14094 & 0.11226 & 0.08374 \\
0.6 & & & & & & & 0.15833 & 0.12995 & 0.10127 & 0.07268 \\
0.7 & & & & & & & & 0.11875 & 0.09030 & 0.06163 \\
0.8 & & & & & & & & & 0.07917 & 0.05064 \\
0.9 & & & & & & & & & & 0.03958 \\
\hline
\end{tabular}

We now turn to the comparative static analysis. Observe from Tables 1 and 2 that an increase in $a$ reduces both firms' profits, whereas an increase in $b$ increases firm $N$ 's profits but reduces firm $S$ 's profits. This asymmetry is due to our assumption of $a \leq b$, or more accurately, it is due to the difference in the effect of changes in quality parameters on the firms' competitive advantage: An increase in $a$, which means a reduction in firm $S$ 's quality disadvantage in product 1 , diminishes firm $N$ 's overall advantage. On the other hand, an increase in $b$ or a reduction in firm $N$ 's quality disadvantage in product 2 enhances firm $N$ 's overall advantage. In other words, an increase in $a$ narrows the quality gap between the firms' bundles, whereas an increase in $b$ widens it. This contrasts with the result in Section 3 that an increase in $a$ or $b$ reduces both firms' profits in the case without bundling, which is due to no strategic interdependence across the products. Observe also from Tables 3 and 4 in the appendix that both social welfare and consumer surplus increase in $a$ and $b$.

The effect of changes in quality parameters on the equilibrium prices is more intricate. (We relegate the numerical results for prices to Tables 5, 6, 7, and 8 in the appendix.) An increase in $a$ lowers $p_{1}^{N}, r^{N}$, and $r^{S}$, whereas its effect on $p_{2}^{S}$ is ambiguous. ${ }^{12}$ This is due to strategic interdependences between the products that mixed bundling creates. Figure 3(a) reveals the following strategic interdependences: (i) the bundles offered by the two firms are substitutes; (ii) product 1 by firm $N$ and the bundle by firm $S$ are substitutes, and so are product 2 by firm $S$ and the bundle by firm $N$; (iii) product 1 and the bundle by firm $N$ are substitutes, and so are product 2 and the bundle by firm $S$; and (iv) product 1 by firm $N$ and product 2 by firm $S$ are complements. Taking these interdependences into account, suppose that the quality of product 1 by firm $S$ improves, that is, the parameter $a$ increases. As the rival firm's disadvantage in product 1 diminishes, firm $N$ will lower both the bundle price $r^{N}$ and stand-alone price $p_{1}^{N}$ of product 1 . The bundle price $r^{S}$ also decreases by (i) and (ii). However, the effect on $p_{2}^{S}$ is ambiguous because a decrease in $r^{N}$ and $r^{S}$ lowers $p_{2}^{S}$ by (ii) and (iii) but a decrease in $p_{1}^{N}$ raises $p_{2}^{S}$ by (iv).

The effect of an increase in $b$ is slightly different. An increase in $b$ lowers both $p_{2}^{S}$ and $r^{s}$ by a reason similar to the one given above. On the other hand, Table 7 shows that the

${ }^{12}$ See, for instance, the case of $b=0.8$ or $b=0.9$ in Table 6 in the appendix. 
effect on $r^{N}$ is ambiguous. ${ }^{13}$ This is because an increase in $b$, by improving the quality of firm $N$ 's bundle, has an effect of pushing up $r^{N}$. Recall that an increase in $a$ also has an effect of raising $r^{S}$. But this effect is smaller than the effect on $r^{N}$ of an increase in $b$ since an increase in $a$ narrows the quality gap between the firms' bundles whereas an increase in $b$ widens it. Thus, an increase in $a$ has a negative overall effect on $r^{s}$, whereas an increase $b$ has an ambiguous overall effect on $r^{N}$. Because of these differential effects on the quality gap, an increase in $b$ unambiguously raises $p_{1}^{N}$, which contrasts with the fact that an increase in $a$ has an ambiguous effect on $p_{2}^{S}$.

We finally establish that, as $b$ gets closer to 1 , that is, as the quality gap in product 2 vanishes, the equilibrium prices with mixed bundling converge to those without bundling.

Proposition 8. Assume that $a \leq b$. We have

$$
\lim _{b \rightarrow 1} p_{1}^{N}=\lim _{b \rightarrow 1} r^{N}=\frac{2(1-a)}{3}, \lim _{b \rightarrow 1} p_{2}^{S}=0 \text {, and } \lim _{b \rightarrow 1} r^{S}=\frac{1-a}{3} .
$$

Proof. See Appendix. $\quad$ Q.E.D.

Observe that the limits are identical to the prices given in Proposition 1 for $b=1$. When the quality gap in product 2 vanishes, it does not matter for the gross payoff whether to purchase firm $N$ 's bundle or to purchase product 1 from firm $N$ and product 2 from firm $S$. This causes $r^{N}$ to be equal to $p_{1}^{N}+p_{2}^{S}$. In addition, $p_{2}^{S}$ goes down to 0 since, otherwise, firm $S$ can increase its profits by slightly lowering the price. This implies that $r^{N}$ is equal to $p_{1}^{N}$ and that the implicit price of product 2 by firm $N$ is thus zero. In short, as the two brands of one product become perfect substitutes, the firms' prices of that product go down to 0 . Therefore, there is no room for bundle discounts and mixed bundling yields the same outcome as the case in Section 3 without bundling.

\section{Conclusion}

We have analyzed the effects of competitive mixed bundling in vertically differentiated product markets. We have shown that, compared to the equilibrium without bundling, (i) prices, profits and social welfare are lower, whereas (ii) consumer surplus is higher in the equilibrium with mixed bundling. In addition, the population of consumers who purchase both products from the same firm is larger in the equilibrium with mixed bundling. These results are largely in line with those obtained in the previous literature, but the reason is quite different as we have expounded in Section 4 since we deal with vertical differentiation.

Further, when the quality gap between brands narrows under no bundling and symmetric mixed bundling, prices and profits decrease but social welfare and consumer surplus increase. The reason is basically that firms compete more intensely when brands become more substitutable. Due to strategic interdependences between the products that mixed bundling

13 See, for instance, the case of $a=0$ or $a=0.1$ in Table 7 in the appendix. 
creates, however, the rates of changes in these equilibrium variables are different. Under mixed bundling, prices and profits decrease more slowly whereas social welfare increase more rapidly as the quality gap decreases.

Asymmetric quality differentiation has yielded more interesting observations with regard to the comparative statics. As shown in Section 4.2, an increase in $a$ reduces both firms' profits, whereas an increase in $b$ increases firm $N$ 's profits but reduces firm $S$ 's profits. This asymmetry is due to the difference in the effect of changes in quality parameters on the firms' competitive advantage: An increase in $a$ narrows the quality gap between the firms' bundles, whereas an increase in $b$ widens it. It has also been shown that prices react to changes in these quality parameters in an interesting way. We have finally shown that the equilibrium prices with mixed bundling converge to those without bundling when the quality gap in one product vanishes, that is, when $b$ gets close to one.

We fully admit that some of our results, particularly those for the effects of mixed bundling on profits and social welfare, are based on the premise that every consumer purchases each of the two products. Without this full market coverage assumption, mixed bundling may increase profits as well as social welfare since the market would expand as a result of price reductions. It would, however, substantially complicate the analysis to dispense with this assumption, and thus we believe it is beyond the scope of the present paper.

Another assumption worth mentioning is that consumers' valuations for the two products are independent. With this independent valuations assumption, we have shown that competition between the firms is completely separated across the products under no bundling, whereas strategic interdependences between the products are created under mixed bundling. This is the reason why profits decrease under mixed bundling. However, if consumers' valuations for the two products are correlated, strategic interdependences between the products exist even without bundling. Then the role of mixed bundling in intensifying competition would be diminished, and thus, the effects of mixed bundling on profits, social welfare, and consumer surplus might be ambiguous. It is an interesting topic to examine mixed bundling under general distributions of consumers' valuations.

The present paper considered the case in which one firm offers a high-quality brand of one product and the other offers a high-quality brand of another product. This is the case of shared quality leadership, according to the terminology of Einhorn (1992). It is also likely in reality that one firm offers high-quality brands of both products. In the alternative case of complete quality leadership, again according to Einhorn's terminology, the aspects of competition would be different because standpoints of firms change. In the case of shared quality leadership, our results indicate that both firms have an incentive to offer bundle discounts. In the case of complete quality leadership, on the other hand, the firm with lowquality brands may avoid mixed bundling for fear of intensified competition, whereas the quality leader may have an incentive to aggressively offer a bundle discount to make use of its quality advantage in both products. This might lead to the non-existence of pure strategy equilibria. Hence, it is not an easy task to discuss the effects of mixed bundling for the case of complete leadership within the present framework. We leave a fuller analysis of this issue to future research. 


\section{Appendix}

This appendix contains all the omitted proofs as well as tables for numerical results. The proof is given in the order of proposition, except for that of Proposition 4 for which the technical lemma given below is needed.

\section{Proof of Proposition 2}

(i) Consider first the case when $\min \left\{r^{N}, r^{S}\right\}=r^{S}$, that is, $r^{S} \leq r^{N}$. Suppose to the effect of contradiction that $r^{S}>p_{1}^{S}+p_{2}^{N}$. We will show that either firm $N$ can increase its profits by raising $p_{2}^{N}$ to $p_{2}^{N^{\prime}}=r^{S}-p_{1}^{S}$ or firm $S$ can increase its profits by raising $p_{1}^{S}$ to $p_{1}^{S^{\prime}}=r^{S}-p_{2}^{N}$. From Figure 2, the firms' profits are

$$
\begin{aligned}
\pi^{N}= & p_{1}^{N} D^{N S}+p_{2}^{N} D^{S N}+r^{N} D^{N N} \\
= & p_{1}^{N}\left(1-\frac{p_{1}^{N}+p_{2}^{S}-r^{S}}{1-a}\right)\left(1-\frac{p_{1}^{N}+p_{2}^{S}-r^{N}}{1-b}\right)+p_{2}^{N} \frac{r^{N}-p_{1}^{S}-p_{2}^{N}}{1-a} \frac{r^{S}-p_{1}^{S}-p_{2}^{N}}{1-b} \\
& +r^{N}\left\{\frac{p_{1}^{N}+p_{2}^{S}-r^{N}}{1-b}\left(1-\frac{p_{1}^{N}+p_{2}^{S}-r^{S}}{1-a}\right)\right. \\
& \left.\quad+\frac{1}{2}\left(\frac{p_{1}^{N}+p_{2}^{S}-r^{S}}{1-a}-\frac{r^{N}-p_{1}^{S}-p_{2}^{N}}{1-a}\right)\left(\frac{p_{1}^{N}+p_{2}^{S}-r^{N}}{1-b}+\frac{r^{S}-p_{1}^{S}-p_{2}^{N}}{1-b}\right)\right\}, \\
\pi^{S}= & p_{1}^{S} D^{S N}+p_{2}^{S} D^{N S}+r^{S} D^{S S} \\
= & p_{1}^{S} \frac{r^{N}-p_{1}^{S}-p_{2}^{N}}{1-a} \frac{r^{S}-p_{1}^{S}-p_{2}^{N}}{1-b}+p_{2}^{S}\left(1-\frac{p_{1}^{N}+p_{2}^{S}-r^{S}}{1-a}\right)\left(1-\frac{p_{1}^{N}+p_{2}^{S}-r^{N}}{1-b}\right) \\
+ & r^{S}\left\{\frac{p_{1}^{N}+p_{2}^{S}-r^{S}}{1-a}\left(1-\frac{p_{1}^{N}+p_{2}^{S}-r^{N}}{1-b}\right)\right. \\
& \left.+\frac{1}{2}\left(\frac{p_{1}^{N}+p_{2}^{S}-r^{N}}{1-b}-\frac{r^{S}-p_{1}^{S}-p_{2}^{N}}{1-b}\right)\left(\frac{p_{1}^{N}+p_{2}^{S}-r^{S}}{1-a}+\frac{r^{N}-p_{1}^{S}-p_{2}^{N}}{1-a}\right)\right\} .
\end{aligned}
$$

Now consider the situation in which firm $S$ raises $p_{1}^{S}$ to $p_{1}^{S^{\prime}}=r^{S}-p_{2}^{N}$ while keeping $p_{2}^{S}$ and $r^{S}$ fixed. Then Figure 3(a) becomes relevant, and firm $S$ 's new profits are

$$
\begin{aligned}
\pi^{S \prime} & =p_{2}^{S} D^{N S}+r^{S} D^{S S}=p_{2}^{S}\left(1-\frac{p_{1}^{N}+p_{2}^{S}-r^{S}}{1-a}\right)\left(1-\frac{p_{1}^{N}+p_{2}^{S}-r^{N}}{1-b}\right) \\
& +r^{S}\left\{\frac{p_{1}^{N}+p_{2}^{S}-r^{S}}{1-a}\left(1-\frac{p_{1}^{N}+p_{2}^{S}-r^{N}}{1-b}\right)+\frac{1}{2} \frac{p_{1}^{N}+p_{2}^{S}-r^{N}}{1-b}\left(\frac{p_{1}^{N}+p_{2}^{S}-r^{S}}{1-a}+\frac{r^{N}-r^{S}}{1-a}\right)\right\} .
\end{aligned}
$$

Thus, we have 


$$
\begin{aligned}
\pi^{S^{\prime}}-\pi^{S} & =\frac{r^{S}-p_{1}^{S}-p_{2}^{N}}{2(1-a)(1-b)}\left[2\left(r^{S}-p_{1}^{S}\right)\left(r^{N}-r^{S}\right)+\left(r^{S}-2 p_{1}^{S}\right)\left(r^{S}-p_{1}^{S}-p_{2}^{N}\right)\right] \\
& =\frac{r^{S}-p_{1}^{S}-p_{2}^{N}}{2(1-a)(1-b)}\left[p_{2}^{N}\left(2 p_{1}^{S}-r^{S}\right)-\left(r^{S}-p_{1}^{S}\right)\left(2 p_{1}^{S}+r^{S}-2 r^{N}\right)\right] .
\end{aligned}
$$

We divide the cases below. First, if $r^{S}>2 p_{1}^{S}$ then we can easily see from the first equality that $\pi^{S^{\prime}}>\pi^{S}$ since $r^{S} \leq r^{N}$ and $r^{S}>p_{1}^{S}+p_{2}^{N}$ by supposition. Second, if $r^{S}<2 p_{1}^{S}$ and $2 p_{1}^{S}+r^{S} \leq 2 r^{N}$ then we can also easily see from the second equality that $\pi^{S^{\prime}}>\pi^{S}$ since $p_{2}^{N}>0 .{ }^{14}$ Third, consider the case when $r^{S}<2 p_{1}^{S}$ and $2 p_{1}^{S}+r^{S}>2 r^{N}$. Since the sign of $\pi^{S^{\prime}}-\pi^{S}$ is the same as that of

$$
p_{2}^{N}-\frac{\left(r^{S}-p_{1}^{S}\right)\left(2 p_{1}^{S}+r^{S}-2 r^{N}\right)}{2 p_{1}^{S}-r^{S}},
$$

we would have $\pi^{S^{\prime}} \leq \pi^{S}$ when $p_{2}^{N} \leq\left(r^{S}-p_{1}^{S}\right)\left(2 p_{1}^{S}+r^{S}-2 r^{N}\right) /\left(2 p_{1}^{S}-r^{S}\right)$. If the last inequality holds, however, it can be established that firm $N$ can increase its profits by raising $p_{2}^{N}$ to $p_{2}^{N^{\prime}}=r^{S}-p_{1}^{S}$ while keeping $p_{1}^{N}$ and $r^{N}$ fixed. By doing so, firm $N^{\prime}$ 's profits change to

$$
\begin{aligned}
\pi^{N^{\prime}}=p_{1}^{N} D^{N S}+r^{N} D^{N N} & =p_{1}^{N}\left(1-\frac{p_{1}^{N}+p_{2}^{S}-r^{S}}{1-a}\right)\left(1-\frac{p_{1}^{N}+p_{2}^{S}-r^{N}}{1-b}\right) \\
& +r^{N}\left\{\frac{1}{2} \frac{p_{1}^{N}+p_{2}^{S}-r^{N}}{1-b}\left(1-\frac{p_{1}^{N}+p_{2}^{S}-r^{S}}{1-a}+1-\frac{r^{N}-r^{S}}{1-a}\right)\right\},
\end{aligned}
$$

and we get

$$
\pi^{N^{\prime}}-\pi^{N}=\frac{r^{S}-p_{1}^{S}-p_{2}^{N}}{2(1-a)(1-b)}\left[2\left(p_{2}^{N}\right)^{2}-\left(3 r^{N}-2 p_{1}^{S}\right) p_{2}^{N}+\left(r^{S}-p_{1}^{S}\right) r^{N}\right]
$$

Since $r^{S}>p_{1}^{S}+p_{2}^{N}$ by supposition, the sign of $\pi^{N^{\prime}}-\pi^{N}$ is the same as that of $2\left(p_{2}^{N}\right)^{2}-\left(3 r^{N}-2 p_{1}^{S}\right) p_{2}^{N}+\left(r^{S}-p_{1}^{S}\right) r^{N}$, and it is an easy exercise to show that this quadratic form is positive when $p_{2}^{N} \leq\left(r^{S}-p_{1}^{S}\right)\left(2 p_{1}^{S}+r^{S}-2 r^{N}\right) /\left(2 p_{1}^{S}-r^{S}\right)$. Fourth, consider the case when $r^{S}=2 p_{1}^{S}$. Note that

$$
\pi^{S^{\prime}}-\pi^{S}=\frac{r^{S}\left(r^{S}-p_{1}^{S}-p_{2}^{N}\right)\left(r^{N}-r^{S}\right)}{2(1-a)(1-b)}
$$

is strictly positive when $r^{N}>r^{S}$, and we are done. If, on the other hand, $r^{N}=r^{S}$ holds then

${ }^{14}$ If $p_{2}^{N}=0$, then $\partial \pi^{N} / \partial p_{2}^{N}=\left[3\left(p_{2}^{N}\right)^{2}-\left(3 r^{N}+2 r^{S}-4 p_{1}^{s}\right) p_{2}^{N}+\left(r^{S}-p_{1}^{S}\right)\left(2 r^{N}-p_{1}^{s}\right)\right] /(1-a)(1-b)>0$ under our supposition of $p_{1}^{S}+p_{2}^{N}<r^{S} \leq r^{N}$. Thus, $p_{2}^{N}=0$ cannot be a part of the equilibrium. 
we have $\pi^{S^{\prime}}=\pi^{S}$. In that case, that is, when $r^{S}=2 p_{1}^{S}$ and $r^{N}=r^{S}$ hold, we have

$$
\pi^{N^{\prime}}-\pi^{N}=\frac{\left(r^{S}-p_{1}^{S}-p_{2}^{N}\right)\left(2 p_{2}^{N}-r^{N}\right)^{2}}{2(1-a)(1-b)},
$$

which is positive unless $r^{N}=2 p_{2}^{N}$ and we are done. Finally, observe that the last possibility of having $r^{S}=2 p_{1}^{S}, r^{N}=2 p_{2}^{N}$, and $r^{N}=r^{S}$ contradicts to our supposition of $r^{S}>p_{1}^{S}+p_{2}^{N}$. This completes the proof for the case of $r^{S} \leq r^{N}$.

(ii) The proof for the case when $\min \left\{r^{N}, r^{S}\right\}=r^{N}$ is symmetric to the previous one. Suppose to the effect of contradiction that $r^{N}>p_{1}^{S}+p_{2}^{N}$. Consider the situation in which firm $N$ raises $p_{2}^{N}$ to $p_{2}^{N^{\prime \prime}}=r^{N}-p_{1}^{S}$ while keeping $p_{1}^{N}$ and $r^{N}$ fixed. Then Figure 3(b) becomes relevant, and firm $N$ 's new profits are

$$
\begin{aligned}
\pi^{N \prime \prime} & =p_{1}^{N} D^{N S}+r^{N} D^{N N}=p_{1}^{N}\left(1-\frac{p_{1}^{N}+p_{2}^{S}-r^{S}}{1-a}\right)\left(1-\frac{p_{1}^{N}+p_{2}^{S}-r^{N}}{1-b}\right) \\
& +r^{N}\left\{\frac{p_{1}^{N}+p_{2}^{S}-r^{N}}{1-b}\left(1-\frac{p_{1}^{N}+p_{2}^{S}-r^{S}}{1-a}\right)+\frac{1}{2} \frac{p_{1}^{N}+p_{2}^{S}-r^{S}}{1-a}\left(\frac{p_{1}^{N}+p_{2}^{S}-r^{N}}{1-b}+\frac{r^{S}-r^{N}}{1-b}\right)\right\} .
\end{aligned}
$$

Thus, we have

$$
\begin{gathered}
\pi^{N^{\prime \prime}-\pi^{N}}=\frac{r^{N}-p_{1}^{S}-p_{2}^{N}}{2(1-a)(1-b)}\left[2\left(r^{N}-p_{2}^{N}\right)\left(r^{S}-r^{N}\right)+\left(r^{N}-2 p_{2}^{N}\right)\left(r^{N}-p_{1}^{S}-p_{2}^{N}\right)\right] \\
=\frac{r^{N}-p_{1}^{S}-p_{2}^{N}}{2(1-a)(1-b)}\left[p_{1}^{S}\left(2 p_{2}^{N}-r^{N}\right)-\left(r^{N}-p_{2}^{N}\right)\left(2 p_{2}^{N}+r^{N}-2 r^{S}\right)\right] .
\end{gathered}
$$

When firm $S$ raises $p_{1}^{S}$ to $p_{1}^{S \prime \prime}=r^{N}-p_{2}^{N}$ while keeping $p_{2}^{S}$ and $r^{S}$ fixed, its profits change to

$$
\begin{aligned}
\pi^{S \prime}=p_{2}^{S} D^{N S}+r^{S} D^{S S} & =p_{2}^{S}\left(1-\frac{p_{1}^{N}+p_{2}^{S}-r^{S}}{1-a}\right)\left(1-\frac{p_{1}^{N}+p_{2}^{S}-r^{N}}{1-b}\right) \\
& +r^{S}\left\{\frac{1}{2} \frac{p_{1}^{N}+p_{2}^{S}-r^{S}}{1-a}\left(1-\frac{p_{1}^{N}+p_{2}^{S}-r^{N}}{1-b}+1-\frac{r^{S}-r^{N}}{1-b}\right)\right\},
\end{aligned}
$$

and we get

$$
\pi^{S^{\prime \prime}}-\pi^{S}=\frac{r^{N}-p_{1}^{S}-p_{2}^{N}}{2(1-a)(1-b)}\left[2 p_{1}^{S}-\left(3 r^{S}-2 p_{2}^{N}\right) p_{1}^{S}+\left(r^{N}-p_{2}^{N}\right) r^{S}\right] .
$$

Observe that (3) and (4) are symmetric to (1) and (2) when $r^{N}, r^{S}, p_{1}^{S}$, and $p_{2}^{N}$ are replaced 
by $r^{S}, r^{N}, p_{2}^{N}$, and $p_{1}^{S}$, respectively. Thus, the same argument as the previous one applies to show that either $\pi^{N^{\prime \prime}}-\pi^{N}>0$ or $\pi^{S^{\prime \prime}}-\pi^{S}>0$ holds. This completes the proof. Q.E.D.

\section{Proof of Proposition 3}

Suppose either $\left(p_{1}^{N}+p_{2}^{S}-r^{S}\right) /(1-a) \geq 1$ or $\left(p_{1}^{N}+p_{2}^{S}-r^{N}\right) /(1-b) \geq 1$ holds. Assume without loss of generality that $a \leq b$. Assume further that $r^{S} \leq r^{N}$. We can in fact show that $r^{S}>r^{N}$ cannot hold when $a \leq b$ in any equilibrium with pure bundling. ${ }^{15}$ Consumer choice can be depicted by a diagram similar to Figure 3, with two cases that depend on whether $r^{N}-r^{S} \leq b-a$ or $r^{N}-r^{S}>b-a$. When $r^{N}-r^{S}>b-a$, the firms' profits are

$$
\begin{aligned}
& \pi^{N}=r^{N} D^{N N}=r^{N}\left\{\frac{1}{2} \frac{1-a+r^{S}-r^{N}}{1-b}\left(1-\frac{r^{N}-r^{S}}{1-a}\right)\right\}, \\
& \pi^{S}=r^{S} D^{S S}=r^{S}\left\{1-\left(\frac{1}{2} \frac{1-a+r^{S}-r^{N}}{1-b}\left(1-\frac{r^{N}-r^{S}}{1-a}\right)\right)\right\} .
\end{aligned}
$$

It is straightforward to show that we cannot have $r^{N}-r^{S}>b-a$ at $r^{N}$ and $r^{S}$ satisfying the first-order condition. Thus, we must have $r^{N}-r^{S} \leq b-a$ and the firms' profits in this case are

$$
\begin{aligned}
& \pi^{N}=r^{N} D^{N N}=r^{N}\left\{\frac{1}{2}\left(1-\frac{1-b+r^{N}-r^{S}}{1-a}+1-\frac{r^{N}-r^{S}}{1-a}\right)\right\}, \\
& \pi^{S}=r^{S} D^{S S}=r^{S}\left\{\frac{1}{2}\left(\frac{1-b+r^{N}-r^{S}}{1-a}+\frac{r^{N}-r^{S}}{1-a}\right)\right\} .
\end{aligned}
$$

From the first-order condition, we get the equilibrium outcome of $r^{N}=(3-4 a+b) / 6$, $r^{S}=(3-2 a-b) / 6, \quad \pi^{N}=(3-4 a+b)^{2} / 36(1-a), \quad$ and $\quad \pi^{S}=(3-2 a-b)^{2} / 36(1-a)$. Then the inequality $\max \left\{\left(p_{1}^{N}+p_{2}^{S}-r^{S}\right) /(1-a),\left(p_{1}^{N}+p_{2}^{S}-r^{N}\right) /(1-b)\right\} \geq 1$ becomes

$$
p_{1}^{N}+p_{2}^{S} \geq \min \left\{\frac{9-4 a-5 b}{6}, \frac{9-8 a-b}{6}\right\}=\frac{9-4 a-5 b}{6} .
$$

Now suppose that firm $S$ lowers $p_{2}^{S}$ to $p_{2}^{S^{\prime}}=(9-4 a-5 b) / 6-p_{1}^{N}-\varepsilon$, where $\varepsilon$ is a small positive real number, while keeping $r^{s}=(3-2 a-b) / 6$ fixed. Then Figure 3(a) becomes relevant, and the difference between firm $S$ 's new profit, denoted by $\pi^{S^{\prime}}$, and the current one is

15 The proof is straightforward and thus omitted. We show in the proof of Proposition 4 that $r^{S} \leq r^{N}$ holds when $a \leq b$ in any equilibrium with mixed bundling. 


$$
\pi^{S^{\prime}}-\pi^{S}=\frac{\varepsilon\left[-12(2(b-a)+3 \varepsilon) p_{1}^{N}-36 \varepsilon^{2}+\varepsilon(45-51 b+6 a)+4(b-a)(9-4 a-5 b)\right]}{36(1-a)(1-b)}
$$

Since $p_{1}^{N} \leq r^{N}=(3-4 a+b) / 6,{ }^{16}$ we have

$$
\begin{aligned}
& -12(2(b-a)+3 \varepsilon) p_{1}^{N}-36 \varepsilon^{2}+\varepsilon(45-51 b+6 a)+4(b-a)(9-4 a-5 b) \\
\geq & -12(2(b-a)+3 \varepsilon) r^{N}-36 \varepsilon^{2}+\varepsilon(45-51 b+6 a)+4(b-a)(9-4 a-5 b) \\
= & 24(b-a)(1-b)+(27-57 b+30 a) \varepsilon-36 \varepsilon^{2} .
\end{aligned}
$$

When $a<b$, the last expression is positive for $\varepsilon$ sufficiently close to 0 . When $a=b$, it becomes $27(1-a) \varepsilon-36 \varepsilon^{2}$, which is also positive for $\varepsilon$ sufficiently close to 0 . Hence, firm $S$ can profitably deviate to $p_{2}^{S^{\prime}}$ by taking sufficiently small $\varepsilon$. Therefore, there is no equilibrium in which $\left(p_{1}^{N}+p_{2}^{S}-r^{S}\right) /(1-a) \geq 1$ or $\left(p_{1}^{N}+p_{2}^{S}-r^{N}\right) /(1-b) \geq 1$ holds. Q.E.D.

\section{Proof of Proposition 5}

The first-order condition is given by the following four equations.

$$
\begin{aligned}
\frac{\partial \pi^{N}}{\partial p_{1}^{N}}= & \frac{1}{(1-a)(1-b)}\left[3\left(p_{1}^{N}\right)^{2}-\left(3 r^{N}+2 r^{S}-4 p_{2}^{S}+4-2 a-2 b\right) p_{1}^{N}\right. \\
& \left.+r^{N}\left(2 r^{S}-2 p_{2}^{S}+2-2 a\right)+\left(r^{S}-p_{2}^{S}+1-a\right)\left(1-b-p_{2}^{S}\right)\right]=0, \\
\frac{\partial \pi^{N}}{\partial r^{N}}= & \frac{1}{2(1-a)(1-b)}\left[3\left(r^{N}\right)^{2}-4\left(1-a+r^{S}\right) r^{N}+2 r^{S}\left(2 p_{1}^{N}+p_{2}^{S}\right)-3\left(p_{1}^{N}\right)^{2}\right. \\
& \left.+4 p_{1}^{N}\left(1-a-p_{2}^{S}\right)+p_{2}^{S}\left(2-2 a-p_{2}^{S}\right)\right]=0, \\
\frac{\partial \pi^{S}}{\partial p_{2}^{S}}= & \frac{1}{(1-a)(1-b)}\left[3\left(p_{2}^{S}\right)^{2}-\left(3 r^{S}+2 r^{N}-4 p_{1}^{N}+4-2 a-2 b\right) p_{2}^{S}\right. \\
& \left.+r^{S}\left(2 r^{N}-2 p_{1}^{N}+2-2 b\right)+\left(r^{N}-p_{1}^{N}+1-b\right)\left(1-a-p_{1}^{N}\right)\right]=0, \text { and } \\
\frac{\partial \pi^{S}}{\partial r^{S}}= & \frac{1}{2(1-a)(1-b)}\left[-4(1-b) r^{S}-\left(r^{N}\right)^{2}+2 r^{N}\left(2 p_{2}^{S}+p_{1}^{N}\right)-3\left(p_{2}^{S}\right)^{2}\right. \\
& \left.+4 p_{2}^{S}\left(1-b-p_{1}^{N}\right)+p_{1}^{N}\left(2-2 b-p_{1}^{N}\right)\right]=0 .
\end{aligned}
$$

When $a=b$, it is straightforward to see that $p_{1}^{N}=p_{2}^{S}$ and $r^{N}=r^{S}$ by inspecting (5)-(8). Let $p=p_{1}^{N}=p_{2}^{S}$ and $r=r^{N}=r^{S}$. Then, from (5) and (6), we get

$$
\begin{aligned}
& 2(1-a)(3 p-2 r)-(4 p-r)(2 p-r)=0 \text { and } \\
& (2 r-4 p+1-a)(r-2 p+1-a)=0 .
\end{aligned}
$$

${ }^{16}$ If $p_{1}^{N}>r^{N}$, then the price $p_{2}^{N}$ of product 2 becomes negative. Recall that we ruled out nonnegative prices. 
The solutions for these equations are

$$
\begin{gathered}
p=\frac{3(1-a)}{4}, \quad r=\frac{1-a}{2} ; \text { and } \\
p=\frac{7(1-a)}{12}, \quad r=\frac{2(1-a)}{3} .
\end{gathered}
$$

The first solution does not satisfy the second-order sufficient condition. To see this, observe from (5) that

$$
\begin{gathered}
\frac{\partial \pi^{N}}{\partial p_{1}^{N}}=\frac{\left[12 p_{1}^{N}-5(1-a)\right]\left[4 p_{1}^{N}-3(1-a)\right]}{16(1-a)^{2}} \text { and } \\
\frac{\partial^{2} \pi^{N}}{\partial\left(p_{1}^{N}\right)^{2}}=\frac{12 p_{1}^{N}-7(1-a)}{2(1-a)^{2}}
\end{gathered}
$$

when $p_{2}^{S}=3(1-a) / 4$ and $r^{N}=r^{S}=(1-a) / 2$. Thus, $p_{1}^{N}=3(1-a) / 4$ does not satisfy the second-order condition. It is easy to see that the remaining solution of $p=7(1-a) / 12$ and $r=2(1-a) / 3$ satisfies the second-order sufficient condition. It is also easy to derive the rest of the equilibrium outcome. Q.E.D.

Characterization of equilibrium when $a \leq b$

For notational simplicity, let

$$
A=1-a, \quad B=1-b, \text { and } K=B\left[16(16 A+9 B)\left(p_{2}^{S}\right)^{2}-312 A B p_{2}^{S}+121 A^{2} B\right] .
$$

Thus, $A$ is the quality gap in product 1 and $B$ is the quality gap in product 2 . We first establish a technical lemma.

Lemma . Assume that $a \leq b$. The equilibrium prices are given as follows:

(i) $p_{2}^{s}$ is the smaller of the two positive real solutions for the cubic equation

$$
\begin{aligned}
& f\left(p_{2}^{S}\right)=576(A-B)\left(p_{2}^{S}\right)^{3}-24 B(37 A-9 B)\left(p_{2}^{S}\right)^{2}-2 A B(605 A-387 B) p_{2}^{S} \\
&+3 A B^{2}(242 A-81 B)=0, \\
& \text { (ii) } p_{1}^{N}= \frac{1}{4 B\left(16 p_{2}^{S}-3 B\right)}\left[\left(2 p_{2}^{S}-B\right) \sqrt{K}-B\left\{24\left(p_{2}^{S}\right)^{2}-6(9 A+2 B) p_{2}^{S}+17 A B\right\}\right], \\
& \text { (iii) } r^{N}= \frac{1}{32 B p_{2}^{S}\left(16 p_{2}^{S}-3 B\right)}\left[\left(4 p_{2}^{S}-B\right)\left(4 p_{2}^{S}+3 B\right) \sqrt{K}+B\left\{320\left(p_{2}^{S}\right)^{3}+48(9 A-4 B)\left(p_{2}^{S}\right)^{2}\right.\right. \\
&\left.\left.-12 B(26 A-3 B) p_{2}^{S}+33 A B^{2}\right\}\right], \text { and } \\
& \text { (iv) } r^{S}= \frac{1}{8 B\left(16 p_{2}^{S}-3 B\right)}\left[\left(4 p_{2}^{S}-B\right) \sqrt{K}+B\left\{80\left(p_{2}^{S}\right)^{2}-12(A+B) p_{2}^{S}-5 A B\right\}\right] .
\end{aligned}
$$


Some remarks on the lemma are in order. First of all, observe that $f\left(p_{2}^{S}\right)=0$ given in part (i) of the lemma becomes $-A^{2}\left[12 p_{2}^{S}-7 A\right]\left[56 p_{2}^{S}+69 A\right]=0$ when $a=b$. Thus we get $p_{2}^{S}=7 A / 12$ and, after putting this into parts (ii), (iii), and (iv) of the lemma, we subsequently get $p_{1}^{N}=7 A / 12$ and $r^{N}=r^{S}=2 A / 3$. This is the solution obtained in Proposition 5 for the symmetric mixed bundling case. Secondly, when $a<b$, the equation $f\left(p_{2}^{S}\right)=0$ has two positive and one negative real solutions. Note that $576(A-B)$, the coefficient of $\left(p_{2}^{S}\right)^{3}$, and the constant term $3 A B^{2}(242 A-81 B)$ are positive. Moreover, it is straightforward to see that $f(7 B / 12) \geq 0, f^{\prime}(7 B / 12)<0$, and $f(2 B / 3)<0 .{ }^{17}$ Thus, we conclude that the equation $f\left(p_{2}^{S}\right)=0$ has two positive real solutions, with the smaller one lying in the half-open interval $[7 B / 12,2 B / 3)$, and one negative solution. Thirdly, the following proof shows that the larger of the two positive real solutions for $f\left(p_{2}^{S}\right)=0$ violates the second-order condition, whereas the smaller one satisfies it. Hence, the equilibrium price of $p_{2}^{S}$ is the smaller of the two positive real solutions for $f\left(p_{2}^{S}\right)=0$, as specified in part (i) of the lemma.

\section{Proof of Lemma}

The first-order condition is given by equations (5) - (8) in the proof of Proposition 5. From (8), $r^{s}$ can be rewritten as

$$
r^{S}=\frac{2 B\left(p_{1}^{N}+2 p_{2}^{S}\right)-\left(p_{1}^{N}+p_{2}^{S}-r^{N}\right)\left(p_{1}^{N}+3 p_{2}^{S}-r^{N}\right)}{4 B} .
$$

Put this back into (5), (6) and (7), and denote the resulting equations by (5)', (6)' and (7)', respectively. Add (5)' and (6)' to get

$$
5\left(r^{N}\right)^{2}-2\left(5 p_{1}^{N}+2 p_{2}^{S}\right) r^{N}+\left(5 p_{1}^{N}-p_{2}^{S}\right)\left(p_{1}^{N}+p_{2}^{S}\right)+4 A B-6 p_{1}^{N}=0 .
$$

Add (6)' and (7)' to get

$$
\begin{aligned}
& \left(2 B+p_{2}^{S}\right)\left(r^{N}\right)^{2}-2\left(A B+p_{1}^{N} p_{2}^{S}+2 p_{2}^{S}\right) r^{N}+2 A B\left(p_{1}^{N}-p_{2}^{S}\right) \\
+ & 2 B\left(\left(p_{1}^{N}\right)^{2}+\left(p_{2}^{S}\right)^{2}+p_{1}^{N} p_{2}^{S}\right)+p_{2}^{S}\left(p_{1}^{N}+3 p_{2}^{S}\right)\left(p_{1}^{N}+p_{2}^{S}\right)+2 A B^{2}=0 .
\end{aligned}
$$

Now solve for $r^{N}$ by using (9) and (10) to get

$$
r^{N}=\frac{10 B\left(p_{1}^{N}\right)^{2}-B(5 A+6 B) p_{1}^{N}-8\left(p_{2}^{S}\right)^{3}+4 B\left(p_{2}^{S}\right)^{2}+7 A B p_{2}^{S}-A B^{2}+2 p_{1}^{N} p_{2}^{S}\left(3 B-4 p_{2}^{S}\right)}{10 B p_{1}^{N}+4 B p_{2}^{S}-8\left(p_{2}^{S}\right)^{2}-5 A B} .
$$

Subtract (7) from (5) to get

17 From part (i) of the lemma, we have $f(7 B / 12)=B^{2}(121 A+245 B)(A-B) / 6 \geq 0$, $f^{\prime}(7 B / 12)=-2 B\left(605 A^{2}-163 A B+168 B^{2}\right)<0$, and $f(2 B / 3)=-B^{2}\left(242 A^{2}-147 A B+224 B^{2}\right) / 3<0$. 


$$
r^{S}=\frac{\left(2 p_{1}^{N}-B\right) r^{N}+(A+B)\left(p_{1}^{N}-p_{2}^{S}\right)-2\left(p_{1}^{N}+p_{2}^{S}\right)\left(p_{1}^{N}-p_{2}^{S}\right)}{2 p_{2}^{S}-B}
$$

Insert (11) into this to get

$$
r^{S}=\frac{2 B\left(p_{1}^{N}\right)^{2}+A B p_{1}^{N}-8\left(p_{2}^{S}\right)^{3}+4(2 A+B)\left(p_{2}^{S}\right)^{2}-5 A B p_{2}^{S}-A^{2} B+2 p_{1}^{N} p_{2}^{S}\left(3 B-4 p_{2}^{S}\right)}{10 B p_{1}^{N}+4 B p_{2}^{S}-8\left(p_{2}^{S}\right)^{2}-5 A B} .
$$

Observe that (11) and (12) solve for $r^{N}$ and $r^{S}$ as functions of $p_{1}^{N}$ and $p_{2}^{S}$.

Now insert (11) and (12) back into (5) to get

$$
\frac{2\left[2 p_{1}^{N}+2 p_{2}^{S}-3 A\right] B}{A B\left[10 B p_{1}^{N}+4 B p_{2}^{S}-8\left(p_{2}^{S}\right)^{2}-5 A B\right]^{2}} \times g\left(p_{1}^{N}, p_{2}^{S}\right)=0,
$$

where

$$
\begin{gathered}
g\left(p_{1}^{N}, p_{2}^{S}\right)=2 B\left(16 p_{2}^{S}-3 B\right)\left(p_{1}^{N}\right)^{2}+B\left[24\left(p_{2}^{S}\right)^{2}-6(9 A+2 B) p_{2}^{S}+17 A B\right] p_{1}^{N} \\
-8 A\left(p_{2}^{S}\right)^{3}-4 A B\left(p_{2}^{S}\right)^{2}+A B(19 A+4 B) p_{2}^{S}-7 A^{2} B^{2}
\end{gathered}
$$

Thus, we have either $2\left(p_{1}^{N}+p_{2}^{S}\right)=3 A$ or $g\left(p_{1}^{N}, p_{2}^{S}\right)=0$. Suppose first that $2\left(p_{1}^{N}+p_{2}^{S}\right)=3 A$ holds in equilibrium. Putting this relation into (11) and (12) gives $r^{N}=(3 A-2 B) / 2$ and $r^{S}=A / 2$. However, since it is straightforward to see that

$$
p_{2}^{S}=\frac{3 A}{2}-p_{1}^{N}, r^{N}=\frac{3 A-2 B}{2} \text {, and } r^{S}=\frac{A}{2}
$$

are not consistent with the second-order condition of $\partial^{2} \pi^{N} / \partial\left(p_{1}^{N}\right)^{2} \leq 0$ and $\partial^{2} \pi^{s} / \partial\left(p_{2}^{s}\right)^{2} \leq 0$, we must have $g\left(p_{1}^{N}, p_{2}^{S}\right)=0$ in equilibrium. Observe that this equation is written as a quadratic equation of $p_{1}^{N}$ and so has two solutions, say $\underline{p}_{1}^{N}$ and $\bar{p}_{1}^{N}$. We will show at the end of the proof that the smaller solution $\underline{p}_{1}^{N}$ cannot satisfy the inequality given in Proposition 3. Thus, we obtain $p_{1}^{N}$ in part (ii) of the lemma as the larger solution $\bar{p}_{1}^{N}$ of $g\left(p_{1}^{N}, p_{2}^{S}\right)=0$. Insert this $p_{1}^{N}$ into (11) and (12), and we get $r^{N}$ and $r^{S}$ as in parts (iii) and (iv) of the lemma.

To derive the cubic equation $f\left(p_{2}^{S}\right)=0$ given in part (i) of the lemma, insert parts (ii), (iii) and (iv) into (8). Then, we get

where

$$
\frac{\partial \pi^{S}}{\partial r^{S}}=\frac{Q \sqrt{K}+R}{1024 A\left(p_{2}^{S}\right)^{2}\left(16 p_{2}^{S}-3 B\right)}=0
$$

$$
\begin{aligned}
& Q=96\left(p_{2}^{S}\right)^{2}+4(44 A-9 B) p_{2}^{S}-33 A B, \\
& R=384(8 A-3 B)\left(p_{2}^{S}\right)^{3}-48 B(26 A-9 B)\left(p_{2}^{S}\right)^{2}-8 A B(242 A+9 B) p_{2}^{S}+363 A^{2} B^{2}, \text { and }
\end{aligned}
$$




$$
K=B\left[16(16 A+9 B)\left(p_{2}^{S}\right)^{2}-312 A B p_{2}^{S}+121 A^{2} B\right]
$$

Thus, we must have $Q \sqrt{K}+R=0$ in equilibrium. We will shortly show that $Q>0$ and $R<0$ in equilibrium. This implies that

$$
Q^{2} K-R^{2}=-1024 A\left(p_{2}^{S}\right)^{2}\left(16 p_{2}^{S}-3 B\right) \times f\left(p_{2}^{S}\right)=0
$$

where

$$
\begin{aligned}
f\left(p_{2}^{S}\right)= & 576(A-B)\left(p_{2}^{S}\right)^{3}-24 B(37 A-9 B)\left(p_{2}^{S}\right)^{2} \\
& -2 A B(605 A-387 B) p_{2}^{S}+3 A B^{2}(242 A-81 B) .
\end{aligned}
$$

We cannot have $p_{2}^{S}=0$ or $p_{2}^{S}=3 B / 16$ in equilibrium. If $p_{2}^{S}=0$, then $p_{1}^{N}, r^{N}$, and $r^{S}$ given in parts (ii), (iii) and (iv) of the lemma become $7 A / 3,(56 A-9 B) / 24$, and $2 A / 3$, respectively. Then, it is easy to show that they are not consistent with the first-order condition. If $p_{2}^{S}=3 B / 16$, then the numerator of $p_{1}^{N}$ in part (ii) of the lemma has a negative value, whereas the denominator of $p_{1}^{N}$ becomes zero. Therefore, we have $f\left(p_{2}^{S}\right)=0$ in equilibrium.

As discussed just before the proof, the equation $f\left(p_{2}^{S}\right)=0$ has two positive real solutions, with the smaller one lying in the half-open interval $[7 B / 12,2 B / 3)$, and one negative solution. We now show that the larger of the two positive real solutions for $f\left(p_{2}^{S}\right)=0$ violates the second-order condition. In particular, we will show that $\partial^{2} \pi^{N} / \partial\left(r^{N}\right)^{2}>0$ at the larger solution. From equation (6) in the proof of Proposition 5, i.e., from the expression of $\partial \pi^{N} / \partial r^{N}$, we have

$$
\frac{\partial^{2} \pi^{N}}{\partial\left(r^{N}\right)^{2}}=-\frac{2 A-3 r^{N}-2 r^{S}}{A B}=\frac{X+Y \sqrt{K}}{16 A B^{2}\left(16 p_{2}^{S}-3 B\right) p_{2}^{S}},
$$

where

$$
\begin{aligned}
& X=B\left[320\left(p_{2}^{S}\right)^{3}+16(11 A-30 B)\left(p_{2}^{S}\right)^{2}-4(176 A-27 B) B p_{2}^{S}+99 A B^{2}\right], \\
& Y=\left(4 p_{1}^{S}+9 B\right)\left(4 p_{1}^{S}-B\right), \text { and } \\
& K=B\left[16(16 A+9 B)\left(p_{2}^{S}\right)^{2}-312 A B p_{2}^{S}+121 A^{2} B\right]
\end{aligned}
$$

The second equality obtains by inserting parts (iii) and (iv) of the lemma into $r^{N}$ and $r^{S}$. Since the smaller of the two positive real solutions for $f\left(p_{2}^{S}\right)=0$ is greater than $7 B / 12$, both the denominator and $Y$ are positive. We will show that $X$ is positive at the larger solution (whereas it is negative at the smaller solution). Observe that $X$ is written as a cubic form of $p_{2}^{S}$. Now, by part (i) of the lemma, $\left(p_{2}^{S}\right)^{3}$ can be written as

$$
\left(p_{2}^{S}\right)^{3}=\frac{24 B(37 A-9 B)\left(p_{2}^{S}\right)^{2}+2 A B(605 A-387 B) p_{2}^{S}-3 A B^{2}(242 A-81 B)}{576(A-B)} .
$$


Further, if we let $B=k A$, where $0 \leq k<1$, then $X$ becomes $\left(k A^{2} /(1-k)\right) h\left(p_{2}^{S}\right)$, where

$$
h\left(p_{2}^{S}\right)=24\left(66-61 k+135 k^{2}\right)\left(p_{2}^{S}\right)^{2}-2\left(143-1719 k+486 k^{2}\right) k A p_{2}^{S}-3 k A^{2}(913-108 k) .
$$

Hence, the sign of $X$ is equal to that of $h\left(p_{2}^{S}\right)$. Since the sign of the coefficient of $\left(p_{2}^{S}\right)^{2}$ in $h\left(p_{2}^{S}\right)$ is positive but the constant term, $-3 k A^{2}(913-108 k)$, is negative, the quadratic equation $h(p)=0$ has one negative and one positive real solution. Denote the positive solution by $\hat{p} .^{18}$ If $\hat{p}$ lies between two positive solutions of $f\left(p_{2}^{S}\right)=0$, the sign of $X$ is positive at the larger solution and is negative at the smaller one. To show this, note that it suffices to establish that $f(\hat{p})<0$, given the shape of $f(\cdot)$. Observe that

$$
f(\hat{p})=-\frac{k^{2} A^{4}}{24\left(66-61 k+135 k^{2}\right)^{3}}[M+N \sqrt{L}],
$$

where

$$
\begin{aligned}
M= & 28697814 k^{7}-2117792385 k^{6}+3543156513 k^{5}+3619710261 k^{4} \\
& +3484409643 k^{3}-2157062886 k^{2}+2299124146 k-1063902906, \\
N= & 59049 k^{5}+3363606 k^{4}-7156107 k^{3}+5607558 k^{2}-2891416 k+1317690, \text { and } \\
L= & 236196 k^{4}-2720628 k^{3}+12442653 k^{2}-5014746 k+4359025 .
\end{aligned}
$$

It can be checked that we have $N>0$ for all $k \in[0,1)$, while $M>0$ for $k \in(0.4386,1)$ and $M<0$ for $k \in[0,0.4386)$. Further, when $k \in[0,0.4386)$, we have $N^{2} L-M^{2}>0$. This establishes that $M+N \sqrt{L}>0$ and so $f(\hat{p})<0$. Proceeding similarly, we can in fact check that the smaller solution satisfies the second-order condition.

Now let us confirm that $Q>0$ and $R<0$ in equilibrium. Observe first that the value of $Q$ at $p_{2}^{S}=7 B / 12$ is $B(209 A+35 B) / 3>0$. It is then easy to see that $Q>0$ for all $p_{2}^{S} \in[7 B / 12,2 B / 3)$ since $Q$ is strictly increasing in $p_{2}^{S}$. Observe next that $R$ is a cubic form of $p_{2}^{S}$, where the coefficient of $\left(p_{2}^{S}\right)^{3}$ as well as the constant term is positive. Thus, $R$ has at most two positive real solutions. Since the values of $R$ evaluated at $p_{2}^{S}=7 \mathrm{~B} / 12$ and at $p_{2}^{S}=2 B / 3$ are both negative, we have $R<0$ for all $p_{2}^{S} \in[7 B / 12,2 B / 3) .^{19}$

Finally, we show that the smaller solution $\underline{p}_{1}^{N}$ of $g\left(p_{1}^{N}, p_{2}^{S}\right)=0$ does not satisfy the inequality in Proposition 3. In particular, we will show that $p_{1}^{N}+p_{2}^{S}-r^{N}>B$ holds. Insert $\underline{p}_{1}^{N}$ into (11) and (12) to get another set of values, $\underline{r}^{N}$ and $\underline{r}^{S}$, as follows:

$18 \hat{p}=k A\left(143-1719 k+486 k^{2}+\sqrt{L}\right) /\left(24\left(66-61 k+135 k^{2}\right)\right)$, where $L$ is defined below.

$19 R=-B^{2}\left(6897 A^{2}-1288 A B+735 B^{2}\right) / 9$ at $p_{2}^{s}=7 B / 12$ and $R=-B^{2}\left(8349 A^{2}-2768 A B+1344 B^{2}\right) / 9$ at $p_{2}^{s}=2 B / 3$. 


$$
\begin{aligned}
& \underline{p}_{1}^{N}=\frac{1}{4 B\left(16 p_{2}^{S}-3 B\right)}\left[-\left(2 p_{2}^{S}-B\right) \sqrt{K}-B\left(24\left(p_{2}^{S}\right)^{2}-6(9 A+2 B) p_{2}^{S}+17 A B\right)\right], \\
& \underline{r}^{N}=\frac{1}{32 B p_{2}^{S}\left(16 p_{2}^{S}-3 B\right)}\left[-\left(4 p_{2}^{S}-B\right)\left(4 p_{2}^{S}+3 B\right) \sqrt{K}+B\left(320\left(p_{2}^{S}\right)^{3}+48(9 A-4 B)\left(p_{2}^{S}\right)^{2}\right.\right. \\
& \left.\left.\quad-12 B(26 A-3 B) p_{2}^{S}+33 A B^{2}\right)\right], \text { and } \\
& \underline{r}^{S}=\frac{1}{8 B\left(16 p_{2}^{S}-3 B\right)}\left[-\left(4 p_{2}^{S}-B\right) \sqrt{K}+B\left(80\left(p_{2}^{S}\right)^{2}-12(A+B) p_{2}^{S}-5 A B\right)\right] .
\end{aligned}
$$

Since

$$
\begin{aligned}
& \frac{12 B p_{2}^{S}+11 A B+\sqrt{K}}{32 p_{2}^{S}}-B=\frac{-20 B p_{2}^{S}+11 A B+\sqrt{K}}{32 p_{2}^{S}} \text { and } \\
& K-\left(20 B p_{2}^{S}-11 A B\right)^{2}=128 B p_{2}^{S}\left[2(A-B) p_{2}^{S}+A B\right]>0,
\end{aligned}
$$

we see that $p_{1}^{N}+p_{2}^{S}-\underline{r}^{N}=\left(12 B p_{2}^{S}+11 A B+\sqrt{K}\right) / 32 p_{2}^{S}>B$. This completes the proof. Q.E.D.

\section{Proof of Proposition 4}

If $A=B$, then $r^{N}=r^{S}=7 A / 12$ and we are done. Hence, let $A>B$. From the lemma, we have

$$
r^{N}-r^{S}=\frac{3\left(4 p_{2}^{S}-B\right) \sqrt{K}+48(8 A-3 B)\left(p_{2}^{S}\right)^{2}-4 B(73 A-9 B) p_{2}^{S}+33 A B^{2}}{32 p_{2}^{S}\left(16 p_{2}^{S}-3 B\right)},
$$

where

$$
K=B\left[16(16 A+9 B)\left(p_{2}^{S}\right)^{2}-312 A B p_{2}^{S}+121 A^{2} B\right] .
$$

Since $p_{2}^{S} \geq 7 B / 12$ as shown in the discussion following the lemma, the denominator is positive and so the sign of $r^{N}-r^{S}$ is the same as that of the numerator. Note also that $3\left(4 p_{2}^{S}-B\right) \sqrt{K}$ in the numerator is positive. Hence, it suffices to show that

$$
\begin{aligned}
& {\left[3\left(4 p_{2}^{S}-B\right) \sqrt{K}\right]^{2}-\left[48(8 A-3 B)\left(p_{2}^{S}\right)^{2}-4 B(73 A-9 B) p_{2}^{S}+33 A B^{2}\right]^{2} } \\
= & 64 A p_{2}^{S}\left(16 p_{2}^{S}-3 B\right)\left[-144(A-B)\left(p_{2}^{S}\right)^{2}+48 B(4 A-3 B) p_{2}^{S}-B^{2}(55 A-27 B)\right]>0
\end{aligned}
$$

or

$$
-144(A-B)\left(p_{2}^{S}\right)^{2}+48 B(4 A-3 B) p_{2}^{S}-B^{2}(55 A-27 B)>0
$$

to prove $r^{N}>r^{S}$. Observe that the proof is completed if we can show that the equilibrium price $p_{2}^{S}$ lies between the solutions of this quadratic equation, that is, $\underline{p}_{2}^{S}<p_{2}^{S}<\bar{p}_{2}^{S}$, where 


$$
\begin{aligned}
& \underline{p}_{2}^{S}=\frac{B\left(8 A-6 B-\sqrt{9 A^{2}-14 A B+9 B^{2}}\right)}{12(A-B)} \text { and } \\
& \bar{p}_{2}^{S}=\frac{B\left(8 A-6 B+\sqrt{9 A^{2}-14 A B+9 B^{2}}\right)}{12(A-B)} .
\end{aligned}
$$

To show this, note that it suffices to establish that $f\left(\underline{p}_{2}^{S}\right)>0$ and $f\left(\bar{p}_{2}^{S}\right)<0$. This is so given the discussion following the lemma on the shape of $f(\cdot)$. For expositional purposes, we let $B=k A$, where $0 \leq k<1$. Observe that

$$
\begin{gathered}
f\left(\underline{p}_{2}^{S}\right)=\frac{B^{2}}{6(A-B)^{2}}\left[\left(605 A^{3}-802 A^{2} B+403 A B^{2}-126 B^{3}\right) \sqrt{9 A^{2}-14 A B+9 B^{2}}\right. \\
\left.-\left(484 A^{4}-151 A^{3} B+349 A^{2} B^{2}-873 A B^{3}+351 B^{4}\right)\right] \\
=\frac{k^{2} A^{4}}{6(1-k)^{2}}\left[\left(605-802 k+403 k^{2}-126 k^{3}\right) \sqrt{9-14 k+9 k^{2}}\right. \\
\left.-\left(484-151 k+349 k^{2}-873 k^{3}+351 k^{4}\right)\right]
\end{gathered}
$$

and

$$
\begin{gathered}
f\left(\bar{p}_{2}^{S}\right)=\frac{B^{2}}{6(A-B)^{2}}\left[-\left(605 A^{3}-802 A^{2} B+403 A B^{2}-126 B^{3}\right) \sqrt{9 A^{2}-14 A B+9 B^{2}}\right. \\
\left.-\left(484 A^{4}-151 A^{3} B+349 A^{2} B^{2}-873 A B^{3}+351 B^{4}\right)\right] \\
=\frac{k^{2} A^{4}}{6(1-k)^{2}}\left[-\left(605-802 k+403 k^{2}-126 k^{3}\right) \sqrt{9-14 k+9 k^{2}}\right. \\
\left.-\left(484-151 k+349 k^{2}-873 k^{3}+351 k^{4}\right)\right] .
\end{gathered}
$$

It can be checked that, for all $k \in[0,1)$,

(i) $605-802 k+403 k^{2}-126 k^{3}>0$,

(ii) $484-151 k+349 k^{2}-873 k^{3}+351 k^{4}>0$, and

(iii) $\left[\left(605-802 k+403 k^{2}-126 k^{3}\right) \sqrt{9-14 k+9 k^{2}}\right]^{2}-\left[484-151 k+349 k^{2}-873 k^{3}+351 k^{4}\right]^{2}$

$=(1-k)^{3}\left[3059969-4532055 k+3920906 k^{2}-2385990 k^{3}+464373 k^{4}-19683 k^{5}\right]>0$.

This establishes that $f\left(\underline{p}_{2}^{S}\right)>0$ and $f\left(\bar{p}_{2}^{S}\right)<0$ and we are done. Q.E.D.

\section{Proof of Proposition 7}

(i) Comparison of equilibrium prices

We use $p_{1}^{N}, p_{2}^{S}, r^{N}$, and $r^{S}$ to denote the equilibrium prices under mixed bundling. The equilibrium prices under no bundling in Proposition 1 are explicitly provided. First of all, recall from the discussion following the lemma that $p_{2}^{S}$ is less than $2(1-b) / 3=2 B / 3$, 
which is the equilibrium price of product 2 charged by firm $S$ under no bundling. Secondly, let us prove that $p_{1}^{N}$ is less than $2(1-a) / 3=2 A / 3$, which is the equilibrium price of product 1 charged by firm $N$ under no bundling. Observe from part (ii) of the lemma that ${ }^{20}$

$$
\frac{2 A}{3}-p_{1}^{N}=\frac{1}{12 B\left(16 p_{2}^{S}-3 B\right)}[X \sqrt{K}+Y]
$$

where

$$
\begin{aligned}
& X=-3\left(2 p_{2}^{S}-B\right), \\
& Y=B\left[72\left(p_{2}^{S}\right)^{2}-2(17 A+18 B) p_{2}^{S}+27 A B\right], \text { and } \\
& K=B\left[16(16 A+9 B)\left(p_{2}^{S}\right)^{2}-312 A B p_{2}^{S}+121 A^{2} B\right] .
\end{aligned}
$$

Since $p_{2}^{S} \geq 7 B / 12$, the denominator is positive whereas $X$ is negative. We can also show that $Y>0 .{ }^{21}$ Hence, the sign of $2 A / 3-p_{1}^{N}$ is the same as that of

$$
Y^{2}-X^{2} K=-8 A B\left(16 p_{2}^{S}-B\right)\left[72\left(p_{2}^{S}\right)^{3}-108 B\left(p_{2}^{S}\right)^{2}+(25 A+36 B) B p_{2}^{S}-15 A B^{2}\right]
$$

Now, by part (i) of the lemma, $\left(p_{2}^{S}\right)^{3}$ can be written as

$$
\left(p_{2}^{S}\right)^{3}=\frac{24 B(37 A-9 B)\left(p_{2}^{S}\right)^{2}+2 A B(605 A-387 B) p_{2}^{S}-3 A B^{2}(242 A-81 B)}{576(A-B)} .
$$

Further, if we let $B=k A$, where $0 \leq k<1$, then $Y^{2}-X^{2} K$ becomes

$$
\begin{aligned}
& -8 k A^{3}\left(16 p_{2}^{S}-3 k A\right)\left[24(1+27 k)\left(p_{2}^{S}\right)^{2}+2\left(705-343 k-144 k^{2}\right) A p_{2}^{S}-3 k A^{2}(282-121 k)\right] \\
= & -8 k A^{3}\left(16 p_{2}^{S}-3 k A\right) h\left(p_{2}^{S}\right),
\end{aligned}
$$

where

$$
h\left(p_{2}^{S}\right)=24(1+27 k)\left(p_{2}^{S}\right)^{2}+2\left(705-343 k-144 k^{2}\right) A p_{2}^{S}-3 k A^{2}(282-121 k) .
$$

Hence, it suffices to show that $h\left(p_{2}^{S}\right)<0$ to prove $2 A / 3-p_{1}^{N}>0$. Observe that the sign of the coefficient of $\left(p_{2}^{S}\right)^{2}$ in $h\left(p_{2}^{S}\right)$ is positive but the constant term, $-3 k A^{2}(282-121 k)$, is negative. Thus, the quadratic equation $h(p)=0$ has one negative and one positive real solution. Denote the positive solution by $\hat{p} .^{22}$ The proof is completed if we can show that

\footnotetext{
${ }^{20}$ We note that $X, Y, M, N, L, h(\cdot)$, and $\hat{p}$ that appear below are different from those in the proof of the lemma, whereas $A, B, K$ as well as $f(\cdot)$ are the same.

${ }^{21}$ Observe that $Y>0$ automatically holds if $B \geq(37-6 \sqrt{30}) A / 18 \approx 0.22981 A$. Otherwise, we can show that $f(\tilde{p})<0$, where $\tilde{p}=\left(17 A+18 B-\sqrt{289 A^{2}-1332 A B+324 B^{2}}\right) / 72$ is the smaller real solution of $Y=0$. This proves that $p_{2}^{S}<\tilde{p}$ and thus $Y>0$ by the discussion following the lemma on the shape of $f(\cdot)$.

$22 \hat{p}=A\left(-705+343 k+144 k^{2}+\sqrt{L}\right) /(24(1+27 k))$, where $L$ is defined below.
} 
$p_{2}^{S}<\hat{p}$. To show this, note that it suffices to establish that $f(\hat{p})<0$. This is so given the discussion following the lemma on the shape of $f(\cdot)$. Observe that

$$
f(\hat{p})=\frac{(1-k) A^{4}}{6(1+27 k)}[M+N \sqrt{L}]
$$

where

$$
\begin{aligned}
M= & -350402625+491721285 k-549117517 k^{2}+296031583 k^{3} \\
& -108880254 k^{4}+14350608 k^{5}+466560 k^{6}, \\
N= & 497025-465814 k+388711 k^{2}-88974 k^{3}+3240 k^{4}, \text { and } \\
L= & 497025-463326 k+454105 k^{2}-136440 k^{3}+20736 k^{4} .
\end{aligned}
$$

It can be checked that, for all $k \in[0,1)$, we have $M<0, N>0$, and $M^{2}-N^{2} L>0$. This establishes that $f(\hat{p})<0$ and we are done.

It remains to show that each firm's bundle price in the equilibrium with mixed bundling is lower than the sum of the stand-alone prices in the equilibrium without bundling. That is, we have to show that

$$
r^{N}<\frac{3-2 a-b}{3}=\frac{2 A+B}{3} \text { and } r^{s}<\frac{3-a-2 b}{3}=\frac{A+2 B}{3} .
$$

The proof of these inequalities is omitted because its steps are almost the same as those used to prove $p_{1}^{N}<2 A / 3 .^{23}$

(ii) Comparison of the population of consumers who purchase both products from the same firm

In the equilibrium with mixed bundling, the population $D^{N N}+D^{S S}$ of consumers who purchase both products from the same firm is equal to $1-D^{N S}$ since there exist no consumers who purchase product 1 from $S$ and product 2 from $N$, i.e., $D^{S N}=0$. Thus, to prove that $D^{N N}+D^{S S}$ is larger in the equilibrium with mixed bundling, it suffices to show $D^{N S}$ is smaller in the equilibrium with mixed bundling.

Recall from Figure 3(a) that

$$
D^{N S}=\left(1-\frac{p_{1}^{N}+p_{2}^{S}-r^{S}}{A}\right)\left(1-\frac{p_{1}^{N}+p_{2}^{S}-r^{N}}{B}\right)
$$

under mixed bundling. It is also easy to see from the lemma that, in the equilibrium with mixed bundling, we have

$$
p_{1}^{N}+p_{2}^{S}-r^{S}=\frac{12(8 A+B) q_{S}-29 A B-\sqrt{K}}{8\left(16 q_{S}-B\right)} \text { and } p_{1}^{N}+p_{2}^{S}-r^{N}=\frac{12 B q_{S}+11 A B-\sqrt{K}}{32 q_{S}}
$$

where

23 Detailed proofs are available upon request. 


$$
K=B\left[16(16 A+9 B)\left(p_{2}^{S}\right)^{2}-312 A B p_{2}^{S}+121 A^{2} B\right] .
$$

Using a method similar to that used for the proof of (i), we can show that

$$
\frac{p_{1}^{N}+p_{2}^{S}-r^{S}}{A}>\frac{1}{3} \text { and } \frac{p_{1}^{N}+p_{2}^{S}-r^{N}}{B}>\frac{1}{3} \text {. }
$$

Hence, we have $D^{N S}<4 / 9$ in the equilibrium with mixed bundling. On the other hand, Proposition 1 shows that $D^{N S}=4 / 9$ in the equilibrium without bundling. This completes the proof. Q.E.D.

\section{Proof of Proposition 8}

It is obvious from part (i) of the lemma that $p_{2}^{S}$ converges to 0 as $B$ gets closer to 0 . Using this fact, we prove that $\lim _{B \rightarrow 0}\left(p_{2}^{S} / B\right)=3 / 5$. Observe that $\lim _{B \rightarrow 0}\left(p_{2}^{S} / B\right)=\lim _{B \rightarrow 0}\left(\partial p_{2}^{S} / \partial B\right)$ by l'Hôpital's rule and that

$$
\begin{aligned}
\frac{\partial p_{2}^{S}}{\partial B} & =-\frac{\partial f\left(p_{2}^{S}\right) / \partial B}{\partial f\left(p_{2}^{S}\right) / \partial p_{2}^{S}} \\
& =\frac{576\left(p_{2}^{S}\right)^{3}+24(37 A-18 B)\left(p_{2}^{S}\right)^{2}-2 A(605 A-774 B)}{2\left[864(A-B)\left(p_{2}^{S}\right)^{2}-24 B(37 A-9 B) p_{2}^{S}-A B(605 A-387 B)\right]}
\end{aligned}
$$

by the Implicit Function Theorem. Since $p_{2}^{S}=\left(p_{2}^{S} / B\right) \cdot B=\left(\partial p_{2}^{S} / \partial B\right) \cdot B$ for $B$ sufficiently close to 0 , we can get the value of $\lim _{B \rightarrow 0}\left(\partial p_{2}^{S} / \partial B\right)$ by inserting $p_{2}^{S}=\left(\partial p_{2}^{S} / \partial B\right) \cdot B$ at $p_{2}^{S}$ in the last expression and then letting $B \rightarrow 0$ as follows:

$$
\lim _{B \rightarrow 0} \frac{\partial p_{2}^{S}}{\partial B}=\frac{6-5 \cdot\left[\lim _{B \rightarrow 0}\left(\partial p_{2}^{S} / \partial B\right)\right]}{5}
$$

Hence, $\lim _{B \rightarrow 0}\left(p_{2}^{S} / B\right)=\lim _{B \rightarrow 0}\left(\partial p_{2}^{S} / \partial B\right)=3 / 5$. This implies that $p_{2}^{S}=3 B / 5$ for $B$ sufficiently close to 0 . It is now easy to obtain

$$
\lim _{B \rightarrow 0} p_{1}^{N}=\lim _{B \rightarrow 0} r^{N}=\frac{2 A}{3}, \text { and } \lim _{B \rightarrow 0} r^{S}=\frac{A}{3}
$$

by inserting $p_{2}^{S}=3 B / 5$ into parts (ii), (iii) and (iv) of the lemma and then letting $B \rightarrow 0$. Q.E.D.

Numerical Results: Tables 3 8

$<$ Table 3> Social welfare under mixed bundling

\begin{tabular}{|c|cccccccccc|}
\hline$a$ & 0 & 0.1 & 0.2 & 0.3 & 0.4 & 0.5 & 0.6 & 0.7 & 0.8 & 0.9 \\
\hline 0 & 0.83333 & 0.84191 & 0.85098 & 0.86060 & 0.87078 & 0.88156 & 0.89294 & 0.90493 & 0.91753 & 0.93071 \\
0.1 & & 0.85 & 0.8586 & 0.86776 & 0.87754 & 0.88795 & 0.89902 & 0.91078 & 0.92321 & 0.93629 \\
0.2 & & & 0.86667 & 0.87530 & 0.88458 & 0.89455 & 0.90525 & 0.91671 & 0.92893 & 0.94189 \\
0.3 & & & & 0.88333 & 0.89201 & 0.90143 & 0.91166 & 0.92274 & 0.93470 & 0.94749 \\
0.4 & & & & & 0.9 & 0.90874 & 0.91836 & 0.92893 & 0.94052 & 0.95312 \\
\hline
\end{tabular}




\begin{tabular}{|l|lccccc|}
\hline 0.5 & 0.91667 & 0.92549 & 0.93539 & 0.94647 & 0.95877 \\
0.6 & & & 0.9333 & 0.94229 & 0.95262 & 0.96446 \\
0.7 & & & 0.95 & 0.95918 & 0.97026 \\
0.8 & & & & & 0.96667 & 0.97631 \\
0.9 & & & & & & \\
\hline
\end{tabular}

$<$ Table 4> Consumer surplus under mixed bundling

\begin{tabular}{|c|cccccccccc|}
\hline a & 0 & 0.1 & 0.2 & 0.3 & 0.4 & 0.5 & 0.6 & 0.7 & 0.8 & 0.9 \\
\hline 0 & 0.04167 & 0.07636 & 0.11125 & 0.14624 & 0.18128 & 0.21627 & 0.25118 & 0.28590 & 0.32046 & 0.35478 \\
0.1 & & 0.1375 & 0.17221 & 0.2071 & 0.24213 & 0.27716 & 0.3121 & 0.34691 & 0.38151 & 0.41588 \\
0.2 & & & 0.23333 & 0.26806 & 0.30298 & 0.33802 & 0.37303 & 0.40791 & 0.44257 & 0.47698 \\
0.3 & & & & 0.32917 & 0.36390 & 0.39887 & 0.43391 & 0.46884 & 0.50364 & 0.53807 \\
0.4 & & & & & 0.425 & 0.45976 & 0.49475 & 0.52977 & 0.56461 & 0.59915 \\
0.5 & & & & & & 0.52083 & 0.55563 & 0.59063 & 0.62558 & 0.66023 \\
0.6 & & & & & & & 0.61667 & 0.65149 & 0.6865 & 0.72128 \\
0.7 & & & & & & & & 0.7125 & 0.74738 & 0.78231 \\
0.8 & & & & & & & & & 0.80833 & 0.84325 \\
0.9 & & & & & & & & & & 0.90417 \\
\hline
\end{tabular}

$<$ Table 5> $p_{1}^{N}$ under mixed bundling

\begin{tabular}{|c|cccccccccc|}
\hline$a \quad b$ & 0 & 0.1 & 0.2 & 0.3 & 0.4 & 0.5 & 0.6 & 0.7 & 0.8 & 0.9 \\
\hline 0 & 0.58333 & 0.59183 & 0.60059 & 0.60955 & 0.61861 & 0.62764 & 0.63647 & 0.64498 & 0.65293 & 0.66021 \\
0.1 & & 0.525 & 0.53351 & 0.54232 & 0.55131 & 0.56037 & 0.56933 & 0.57797 & 0.58610 & 0.59350 \\
0.2 & & & 0.46667 & 0.47519 & 0.48405 & 0.49307 & 0.50210 & 0.51090 & 0.51922 & 0.52677 \\
0.3 & & & & 0.40833 & 0.41689 & 0.42579 & 0.43484 & 0.44380 & 0.45226 & 0.46003 \\
0.4 & & & & & 0.35 & 0.35859 & 0.36755 & 0.37658 & 0.38531 & 0.39327 \\
0.5 & & & & & & 0.29167 & 0.30029 & 0.30931 & 0.31825 & 0.32646 \\
0.6 & & & & & & & 0.23333 & 0.24202 & 0.25106 & 0.25961 \\
0.7 & & & & & & & & 0.175 & 0.18377 & 0.19265 \\
0.8 & & & & & & & & & 0.11667 & 0.12553 \\
0.9 & & & & & & & & & & 0.05833 \\
\hline
\end{tabular}

$<$ Table 6> $p_{2}^{s}$ under mixed bundling

\begin{tabular}{|c|cccccccccc|}
\hline$a \quad b$ & 0 & 0.1 & 0.2 & 0.3 & 0.4 & 0.5 & 0.6 & 0.7 & 0.8 & 0.9 \\
\hline 0 & 0.58333 & 0.52930 & 0.47390 & 0.41723 & 0.35941 & 0.30062 & 0.24105 & 0.18096 & 0.12058 & 0.06018 \\
0.1 & & 0.525 & 0.47089 & 0.41528 & 0.35827 & 0.30005 & 0.24085 & 0.18093 & 0.12061 & 0.06020 \\
0.2 & & & 0.46667 & 0.41246 & 0.35658 & 0.29917 & 0.24049 & 0.18085 & 0.12063 & 0.06022 \\
0.3 & & & & 0.40833 & 0.35401 & 0.29778 & 0.23989 & 0.18070 & 0.12063 & 0.06024 \\
0.4 & & & & & 0.35 & 0.29551 & 0.23885 & 0.18037 & 0.12062 & 0.06026 \\
0.5 & & & & & & 0.29167 & 0.23695 & 0.17971 & 0.12053 & 0.06029 \\
0.6 & & & & & & & 0.23333 & 0.17829 & 0.12025 & 0.06032 \\
0.7 & & & & & & & & 0.175 & 0.11942 & 0.06031 \\
0.8 & & & & & & & & & 0.11667 & 0.06012 \\
0.9 & & & & & & & & & & 0.05833 \\
\hline
\end{tabular}


$<$ Table $7>r^{N}$ under mixed bundling

\begin{tabular}{|c|cccccccccc|}
\hline$a$ & 0 & 0.1 & 0.2 & 0.3 & 0.4 & 0.5 & 0.6 & 0.7 & 0.8 & 0.9 \\
\hline 0 & 0.66667 & 0.66202 & 0.65816 & 0.65520 & 0.65324 & 0.65241 & 0.65272 & 0.65433 & 0.65715 & 0.66128 \\
0.1 & & 0.6 & 0.59540 & 0.59170 & 0.58899 & 0.58745 & 0.58720 & 0.58828 & 0.59079 & 0.59469 \\
0.2 & & & 0.53333 & 0.52878 & 0.52526 & 0.52290 & 0.52191 & 0.52238 & 0.52446 & 0.52810 \\
0.3 & & & & 0.46667 & 0.46220 & 0.45890 & 0.45701 & 0.45677 & 0.45820 & 0.46155 \\
0.4 & & & & & 0.4 & 0.39562 & 0.39267 & 0.39144 & 0.39219 & 0.39503 \\
0.5 & & & & & & 0.33333 & 0.32908 & 0.32664 & 0.32638 & 0.32857 \\
0.6 & & & & & & & 0.26667 & 0.26263 & 0.26097 & 0.26223 \\
0.7 & & & & & & & & 0.2 & 0.19632 & 0.19609 \\
0.8 & & & & & & & & & 0.13333 & 0.13048 \\
0.9 & & & & & & & & & & 0.06667 \\
\hline
\end{tabular}

$<$ Table 8> $r^{S}$ under mixed bundling

\begin{tabular}{|c|cccccccccc|}
\hline$a \quad b$ & 0 & 0.1 & 0.2 & 0.3 & 0.4 & 0.5 & 0.6 & 0.7 & 0.8 & 0.9 \\
\hline 0 & 0.66667 & 0.63166 & 0.59672 & 0.56196 & 0.52749 & 0.49346 & 0.45997 & 0.42714 & 0.39504 & 0.36376 \\
0.1 & & 0.6 & 0.56500 & 0.53009 & 0.49539 & 0.46108 & 0.42731 & 0.39420 & 0.36190 & 0.33048 \\
0.2 & & & 0.53333 & 0.49833 & 0.46345 & 0.42886 & 0.39476 & 0.36135 & 0.32880 & 0.29720 \\
0.3 & & & & 0.46667 & 0.43168 & 0.39684 & 0.36240 & 0.32864 & 0.29574 & 0.26395 \\
0.4 & & & & & 0.4 & 0.36501 & 0.33026 & 0.29608 & 0.26280 & 0.23072 \\
0.5 & & & & & & 0.33333 & 0.29836 & 0.26375 & 0.22999 & 0.19752 \\
0.6 & & & & & & & 0.26667 & 0.23173 & 0.19739 & 0.16446 \\
0.7 & & & & & & & & 0.2 & 0.16513 & 0.13140 \\
0.8 & & & & & & & & & 0.13333 & 0.09869 \\
0.9 & & & & & & & & & & 0.06667 \\
\hline
\end{tabular}

\section{References}

Adams, W. and Yellen, J. (1976), "Commodity bundling and the burden of monopoly," Quarterly Journal of Economics, 90, pp. 475-498.

Anderson, S. and Leruth, L. (1993), "Why firms may prefer not to price discriminate via mixed bundling,” International Journal of Industrial Organization, 11, pp. 49-61.

Armstrong, M. and Vickers, J. (2010), “Competitive non-linear pricing and bundling," Review of Economic Studies, 77, pp. 30-60.

Bakos, Y. and Brynjolfsson, E. (1999), "Bundling information goods: Pricing, profits and efficiency,” Marketing Science, 45, pp. 1613-1630.

Economides, N. (1993), “Mixed bundling in duopoly,” manuscript. 
Einhorn, M. (1992), “Mix and match compatibility with vertical product dimensions,” RAND Journal of Economics, 23, pp. 535-547.

Gans, J. and King, S. (2006), “Paying for loyalty: Product bundling in oligopoly,” Journal of Industrial Economics, 54, pp. 43-62.

Kobayashi, B. (2005), "Does economics provide a reliable guide to regulating commodity bundling by firms? A survey of the economic literature," Journal of Competition Law and Economics, 1, pp. 707-746.

Matutes, C. and Regibeau, P. (1988), ““Mix and Match”: Product compatibility without network externalities,” Rand Journal of Economics, 19, pp. 221-234.

Matutes, C. and Regibeau, P. (1992), "Compatibility and bundling of complementary goods in a duopoly,” Journal of Industrial Economics, 40, pp. 37-54.

McAfee, P., McMillan, J., and Whinston, M. (1989), "Multiproduct monopoly, commodity bundling and correlation of values,” Quarterly Journal of Economics, 104, pp. 371-384.

Nalebuff, B. (2004), “Bundling as an entry barrier,” Quarterly Journal of Economics, 119, pp. 159-187.

Reisinger, M. (2006), "Product bundling and the correlation of valuations in duopoly," manuscript.

Schmalensee, R. (1982), “Commodity bundling by a single-product monopolist," Journal of Law and Economics, 119, pp. 159-187.

Stole, L. (2007), "Price discrimination and competition," in Handbook of Industrial Organization: Volume III, (eds. M. Armstrong and R. Porter), North-Holland, Amsterdam, pp. 2221-2300.

Thanassoulis, J. (2007), “Competitive mixed bundling and consumer surplus," Journal of Economics \& Management Strategy, 16(2), pp. 437-467.

Whinston, M. (1990), “Tying, foreclosure, and exclusion,” American Economic Review, 80, pp. 837-859. 